\title{
Tsunami arrival time detection system applicable to discontinuous time series data with outliers
}

\author{
Jun-Whan Lee, Sun-Cheon Park, Duk Kee Lee, and Jong Ho Lee \\ National Institute of Meteorological Sciences, 33, Seohobuk-ro, Seogwipo-si, Jeju-do, 63568, Rep. of Korea \\ Correspondence to: Sun-Cheon Park (suncheon@korea.kr)
}

Received: 4 May 2016 - Published in Nat. Hazards Earth Syst. Sci. Discuss.: 7 June 2016

Revised: 18 November 2016 - Accepted: 19 November 2016 - Published: 9 December 2016

\begin{abstract}
Timely detection of tsunamis with water level records is a critical but logistically challenging task because of outliers and gaps. Since tsunami detection algorithms require several hours of past data, outliers could cause false alarms, and gaps can stop the tsunami detection algorithm even after the recording is restarted. In order to avoid such false alarms and time delays, we propose the Tsunami Arrival time Detection System (TADS), which can be applied to discontinuous time series data with outliers. TADS consists of three algorithms, outlier removal, gap filling, and tsunami detection, which are designed to update whenever new data are acquired. After calibrating the thresholds and parameters for the Ulleung-do surge gauge located in the East Sea (Sea of Japan), Korea, the performance of TADS was discussed based on a 1-year dataset with historical tsunamis and synthetic tsunamis. The results show that the overall performance of TADS is effective in detecting a tsunami signal superimposed on both outliers and gaps.
\end{abstract}

\section{Introduction}

A tsunami is one of the most devastating natural phenomena, and it can be caused by several events, such as earthquakes, submarine landslides, subaerial landslides, volcanic eruptions, asteroid and comet impacts, and man-made explosions (Pugh and Woodworth, 2014). The eastern coast of the Korean Peninsula is not exempt from tsunamis: the peculiar topographic conditions of the East Sea, where the Yamato Rise strongly affects the propagation of tsunamis, cause high tsunami energy concentration at the coast (Cho and Lee, 2013). A low probability exists for tsunamis to occur in the East Sea. However, if and when they do occur, they pose a high risk of damage to not only Korea but also to neighboring countries. For example, two tsunamis in 1983 and 1993, which originated near the western coast of Akita and Hokkaido, Japan, respectively, caused severe damage along the eastern coast of the Korean Peninsula (Fig. 1).

The Korea Meteorological Administration (KMA), as the government's meteorological organization, is responsible for issuing information on tsunamis. To monitor tsunamis, the KMA has operated a surge gauge (aerial ultrasonic type) at Ulleung-do since 1999. Ulleung-do, located in the East Sea, plays a critical role in tsunami hazard mitigation of the Korean Peninsula because it can confirm the approach of tsunamis $30 \mathrm{~min}$ or more before they impact the eastern coast (Fig. 1). However, when the Tōhoku, Japan, tsunami occurred in 2011, even though a post analysis revealed it to be a small tsunami (less than $0.3 \mathrm{~m}$ ), the KMA could not announce important properties of the tsunami, such as its arrival time and wave height, in a press release because of its lack of a tsunami detection system (Yoon et al., 2012). In the aftermath of the Tōhoku tsunami, the National Institute of Meteorological Sciences (NIMS), a government-affiliated organization of the KMA, saw the necessity of developing a tsunami detection system that automatically provides prompt notification.

Because of the infrequent occurrence of large tsunamis in the East Sea, an important technical requirement for detecting tsunamis using the Ulleung-do surge gauge is a sensitive tsunami detection algorithm. To detect a tsunami automatically, several tsunami detection algorithms have been developed around the world based on specific purposes and limitations. Mofjeld (1997) developed a deep-ocean assessment and reporting of tsunamis (DART) algorithm that uses a cubic polynomial fit to the data over the preceding $3 \mathrm{~h}$ 


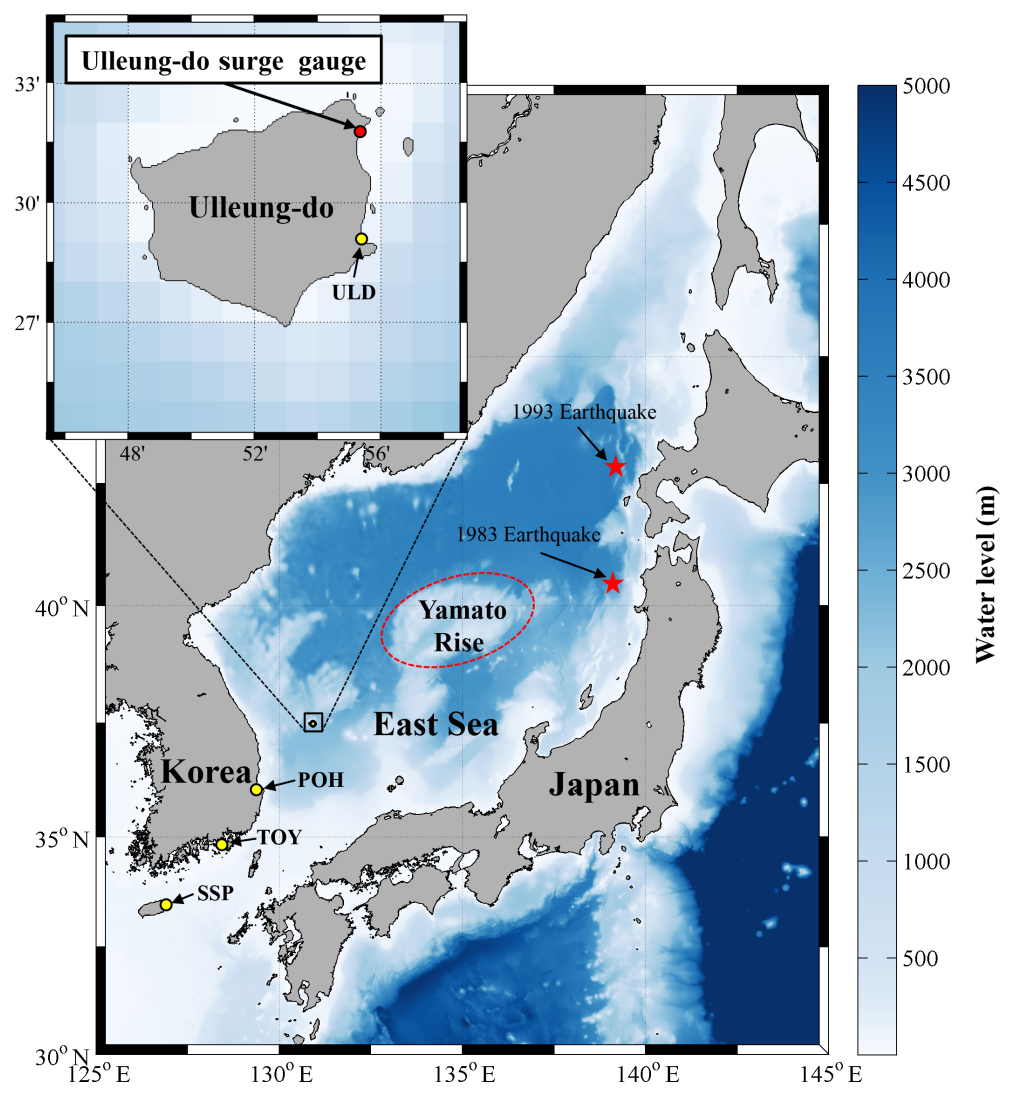

Figure 1. Study area and locations of the Ulleung-do surge gauge (red circle), tide stations (yellow circles), Yamato Rise (red dotted circle), and the epicenters of the 1983 and 1993 earthquakes (red stars).

(Meinig et al., 2005). Several refinements to this algorithm were proposed. Beltrami (2008) modified the DART algorithm based on the artificial neural networks (ANNs) to update the coefficients of every sampling interval. Because the DART algorithm does not provide information on tsunami height but only on arrival time, Beltrami (2011) extended the length of the interval between the actual and prediction times. Bressan and Tinti (2012) proposed a tsunami early detection algorithm (TEDA) designed to detect an anomalous water level based on two slope-based algorithms: tsunami detection and secure detection. The TEDA was successfully calibrated and tested on both synthetic tsunamis and historical tsunami records (Bressan and Tinti, 2012; Bressan et al., 2013). Pérez et al. (2013) introduced a real-time automatic tsunami detection algorithm based on a variance method that was developed within the TRANSFER (Tsunami Risk and Strategies for the European Region) project. However, there was no attempt to combine several tsunami detection algorithms to not only detect weak tsunami signals but also to reduce the probability of false alarms.

The Ulleung-do surge gauge often experiences unexpected gaps or missing points that cause major difficulties in detecting tsunamis. These difficulties are explained by occurrences such as a failure of the recording or interruption of the communication network, aging equipment, and mistakes by field staff (Ustoorikar and Deo, 2008). When data are lost or incomplete, the tsunami detection algorithms that require several hours of data get stopped even after the recording is restarted. For long gaps that are expected to include complex patterns, existing interpolation methods might not be suitable to fill the gaps. Thus, several kinds of soft computing techniques for long gaps have been developed. These include chaos theory, genetic programming, empirical orthogonal functions, and artificial neural networks (ANNs) (Elshorbagy et al., 2002; Nitsure et al., 2014; Tolkova, 2009; Pashova and Popova, 2011). Recently, Lee and Park (2016) developed a gap-filling algorithm based on ANNs and an end-point fixing method (EPFM). Although the soft computing techniques are quite accurate, these applications require considerable computing time. In order to overcome these kinds of shortcomings, Lee and Park (2015) developed a gap-filling algorithm that is similar to Lee and Park's (2016) method, but they used a moving average filter rather than ANNs. However, these methods mentioned above are unnecessarily complex for short gaps where linear change is expected and so a linear interpolation may be enough. Thus, in order to deal with gaps efficiently, a tsunami detection system requires a gap- 


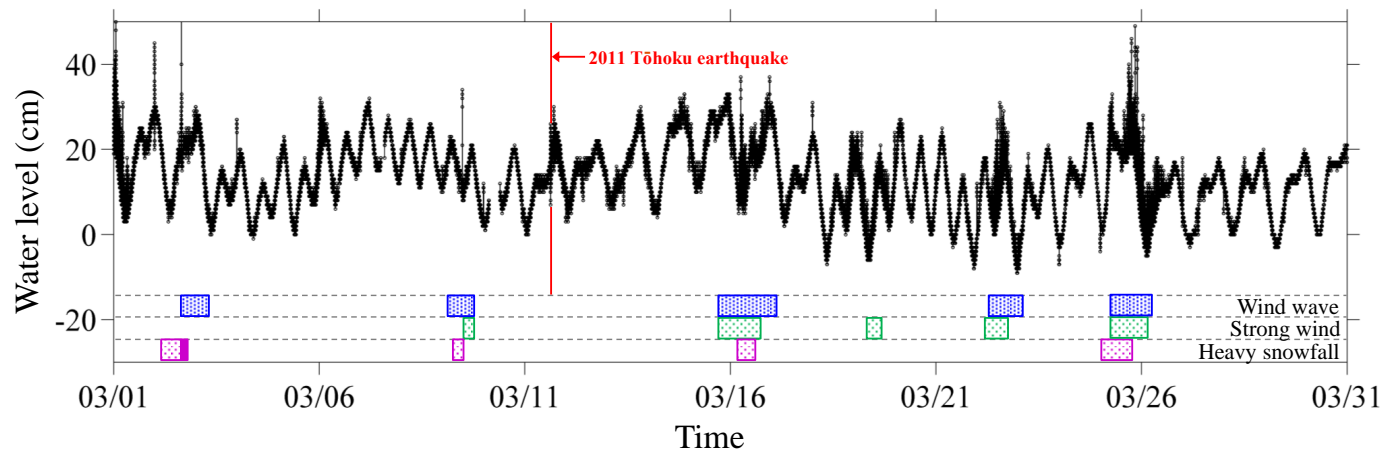

Figure 2. Time series of the Ulleung-do surge gauge with a special weather report from the KMA. The dotted rectangles represent the following advisories: wind wave (blue), strong wind (green), and heavy snow (purple). The filled rectangle represents a heavy snow warning (purple). The red vertical line labeled "2011 Tōhoku Earthquake" denotes the time of the earthquake.

filling algorithm that applies different methods depending on the gap size.

Detecting tsunamis using the Ulleung-do surge gauge is logistically challenging because onshore measurements are usually associated with high background noise (Joseph, 2011). In addition, outliers are derived from various problems related to meteorological events or electrical malfunctions occurring in water level sensor data streams, for example (Fig. 2). When the outliers are mixed with normal data, the tsunami detection algorithms that require several hours of past data could cause a false alarm. Because outlier removal (as well as the anomaly detection, despiking, and noise removal) has been researched for a long time, various techniques have been developed. Ehrentreich and Sümmchen (2001) used a wavelet transform method to remove the spikes from the Raman spectra. Feuerstein et al. (2009) developed a despiking algorithm based on filtering methods using clinical data. Goring and Nikora (2002) and Jesson et al. (2013) presented a phase-space thresholding method that is applied to automated post-processing software to remove spikes from acoustic Doppler velocimeter data (Jesson et al., 2015). However, these methods require a complete set of data or data in a batch. Thus, they are not suitable for real-time or near real-time applications (Hill et al., 2009). To perform in real time or near real time, the outlier removal algorithm must consider the data stream sequentially or the outlier should be detected immediately after it appears. Several studies have defined a window that steps through the data stream to operate in real time. The most up-to-date survey on the windowbased outlier removal algorithm was provided by Gupta et al. (2014). Yamanishi and Takeuchi (2002) developed an online discounting learning algorithm that gradually forgets the effect of past data. Hill et al. (2009) developed an outlier removal algorithm based on dynamic Bayesian networks that adds new state variables over time. Hill and Minsker (2010) developed an outlier removal algorithm based on a datadriven univariate autoregressive model and corresponding prediction interval. However, most of these algorithms that predict the subsequent set of chronologically sequential data using soft computing techniques require huge memory and considerable computation time. Thus, the tsunami detection system requires an outlier removal algorithm that could obviate outliers very quickly within the time interval of data acquisition.

Overall, a tsunami detection system should be designed for the detection of a tsunami signal superimposed on both an outlier and gap. This study presents a tsunami detection system applicable to discontinuous time series data with outliers, which we call TADS (Tsunami Arrival time Detection System). The $10 \mathrm{~s}$ interval data of the Ulleung-do surge gauge recorded from 1 to 31 March 2011 were employed to calibrate the parameters of TADS, in which not only outliers and gaps but also the 2011 Tōhoku tsunami signals were included (Fig. 2). Outliers that may have resulted from meteorological events were found in similar periods identified in special weather reports. In addition, suspicious gaps lasting $6 \mathrm{~h}$ were found in the data of the day before the 2011 Tōhoku earthquake. After calibrating the parameters, the performance of TADS was demonstrated based on a 1year dataset with historical tsunamis and synthetic tsunamis.

\section{TADS (Tsunami Arrival time Detection System)}

TADS is basically comprised of three major algorithms that are designed to operate within the time interval of data acquisition (Fig. 3): (1) outlier removal algorithm (red dotted box), which is divided into three modes: start mode, keep mode, and end mode; (2) gap-filling algorithm (blue dotted box), which is divided into two sub-algorithms depending on gap sizes: SGFA (Short Gap-Filling Algorithm) and LGFA (Long Gap-Filling Algorithm); and (3) tsunami detection algorithm (green dotted box), which is divided into three subalgorithms: DART, SLOPE, and TIDE. The alarm is divided into three levels depending on TDI (Tsunami Detection In- 


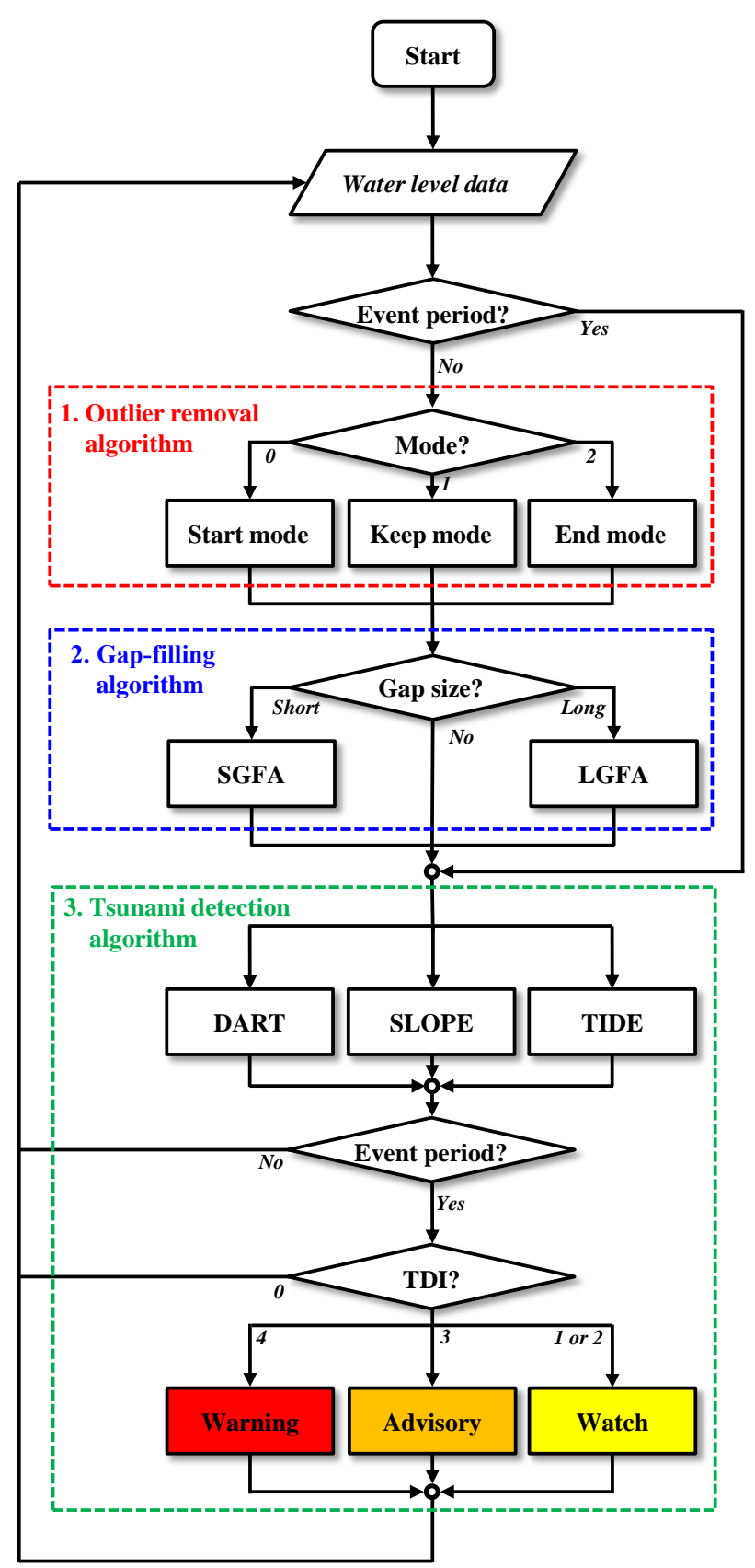

Figure 3. Flow of TADS. The system is composed of three major algorithms: outlier removal (red dotted box), gap filling (blue dotted box), and tsunami detection (green dotted box). SGFA stands for Short Gap-Filling Algorithm; LGFA stands for Long Gap-Filling Algorithm; TDI stands for Tsunami Detection Index.

dex), the degree of tsunami detection triggered: warning, advisory, and watch.

Since most of the tsunami detection algorithm is designed to detect a wave that changes more than expected, the tsunami detection algorithm can not distinguish a tsunami from a record that contains contributions from swells, lo- cal seiches, storm surges, and so on (Joseph, 2011). If the tsunami detection algorithm is applied to the data of the Ulleung-do surge gauge without any restriction, then the tsunami alarm will be issued for not only tsunamis but also for every event mentioned above. Also, even though the outlier removal and gap-filling algorithms are useful for the tsunami detection system, these algorithms could distort a tsunami wave. The outlier removal algorithm could remove a tsunami wave by misunderstanding a tsunami wave as an outlier. Furthermore, the gap-filling algorithm could overestimate or underestimate a tsunami wave, which could mislead to a false alarm. For these reasons, we introduced a concept of an event period: during an event period, the TADS bypasses the outlier removal and gap-filling algorithms and checks for the alarm with the tsunami detection algorithm, while outside an event period, TADS bypasses the alarm of the tsunami detection algorithm. Since earthquakes are responsible for approximately $82 \%$ of tsunamis according to the tsunami database (Joseph, 2011), we confined the starting point of the event period to the origin time based on seismic information. Conversely, the end point of the event period is set to the estimated time when a tsunami sufficiently elapses based on a numerical simulation. In the remainder of this section, the methodology of each algorithm will be described in detail. How the parameters of TADS are determined will be explained in the next session.

\subsection{Outlier removal algorithm}

An outlier removal algorithm performs one of the three modes at every new data acquisition. The initiation is set to the start mode, and it searches for the point at which the outlier begins based on several starting conditions. Once the outlier is detected, the outlier removal algorithm removes the outlier and changes the mode to the keep mode for the next datum. The keep mode continues to remove the data until meeting the predefined time steps. Then the mode is changed to the end mode, which keeps removing the data until satisfying one of the ending conditions. Once the ending condition is triggered, the mode returns to the start mode. The full process of modes and conditions are described below.

\subsubsection{Start mode}

The basic concept of the start mode is that the point at which the difference in wave height between neighboring points surpasses the threshold is designated as an outlier (Fig. 4a). In order to deal with gaps (which will be explained later), a moving window of the most recent 7-point data, in which each point is numbered in ascending order from zero to six going backwards in time, is defined. Figure 4 a shows the case where point 3 and point 6 are gaps. The wave height and its time information of point are hereafter referred to as $h$ and $t$ with a subscript indicating the point number. Point 5 is the target point that determines whether the point is an outlier 
Table 1. Conditions and thresholds of an outlier removal algorithm.

\begin{tabular}{|c|c|c|c|c|c|}
\hline Mode & Category & $\begin{array}{c}\text { Condition } \\
\text { name }\end{array}$ & Condition & $\begin{array}{l}\text { Threshold } \\
\text { name }\end{array}$ & Threshold \\
\hline Start & $\begin{array}{l}\text { SIF1 } \\
\text { SIF2 }\end{array}$ & $\begin{array}{l}\text { S02. } \\
\text { S03. } \\
\text { S04. } \\
\text { S05. } \\
\text { S06. } \\
\text { S07. } \\
\text { S08. } \\
\text { S09. } \\
\text { S10. } \\
\text { S11. }\end{array}$ & $\begin{array}{l}\left(h_{6}=\mathrm{NaN}\right) \\
\operatorname{abs}\left(h_{5}-h_{\mathrm{g}}\right)>\mathrm{THh} \\
\left(h_{6} \neq \mathrm{NaN}\right) \\
\left(\operatorname{sgn}\left(h_{4}-\mathrm{h}_{5}\right) \geq 0\right) \text { and }\left(h_{4}-h_{5}>\mathrm{TH} 4\right) \\
\left(\operatorname{sgn}\left(h_{4}-h_{5}\right)<0\right) \text { and }\left(h_{4}-h_{5}<-\mathrm{TH} \_4\right) \\
\left(\operatorname{sgn}\left(h_{3}-h_{5}\right) \geq 0\right) \text { and }\left(h_{3}-h_{5}>\mathrm{TH} 3\right) \\
\left(\operatorname{sgn}\left(h_{3}-h_{5}\right)<0\right) \text { and }\left(h_{3}-h_{5}<-\mathrm{TH} 3\right) \\
\left(\operatorname{sgn}\left(h_{2}-h_{5}\right) \geq 0\right) \text { and }\left(h_{2}-h_{5}>\mathrm{TH} 2\right) \\
\left(\operatorname{sgn}\left(h_{2}-h_{5}\right)<0\right) \text { and }\left(h_{2}-h_{5}<-\mathrm{TH} 2\right) \\
\left(\operatorname{sgn}\left(h_{1}-h_{5}\right) \geq 0\right) \text { and }\left(h_{1}-h_{5}>\mathrm{TH} 1\right) \\
\left(\operatorname{sgn}\left(h_{1}-h_{5}\right)<0\right) \text { and }\left(h_{1}-h_{5}<-\mathrm{TH} \_1\right) \\
\left(\operatorname{sgn}\left(h_{0}-h_{5}\right) \geq 0\right) \text { and }\left(h_{0}-h_{5}>\mathrm{TH} 0\right) \\
\left(\operatorname{sgn}\left(h_{0}-h_{5}\right)<0\right) \text { and }\left(h_{0}-h_{5}<-\mathrm{TH} 0\right)\end{array}$ & $\begin{array}{l}\text { TH4 } \\
\text { TH_4 } \\
\text { TH3 } \\
\text { TH_3 } \\
\text { TH2 } \\
\text { TH_2 } \\
\text { TH1 } \\
\text { TH_1 } \\
\text { TH0 } \\
\text { TH_0 }\end{array}$ & $\begin{array}{l}3 \mathrm{~cm} \\
3 \mathrm{~cm} \\
3 \mathrm{~cm} \\
9 \mathrm{~cm} \\
3 \mathrm{~cm} \\
10 \mathrm{~cm} \\
4 \mathrm{~cm} \\
10 \mathrm{~cm} \\
4 \mathrm{~cm} \\
10 \mathrm{~cm}\end{array}$ \\
\hline End & $\begin{array}{l}\text { EIF1 } \\
\text { EIF2 } \\
\text { EIF3 }\end{array}$ & $\begin{array}{l}\text { E03. } \\
\text { E04. } \\
\text { E05. } \\
\text { E06. } \\
\text { E07. }\end{array}$ & $\begin{array}{l}\left(h_{5}=\mathrm{NaN}\right) \\
\left(\operatorname{sgn}\left(h_{4}-h_{6}\right) \neq S \text { or } 0\right) \text { and }\left(\operatorname{abs}\left(h_{\mathrm{s}}-h_{6}\right) \leq \mathrm{THS} 1\right) \\
\left(h_{5} \neq \mathrm{NaN}\right) \text { and }\left(h_{6}=\mathrm{NaN}\right) \\
\left(\operatorname{sgn}\left(h_{4}-h_{5}\right) \neq S \text { or } 0\right) \text { and }\left(\operatorname{abs}\left(h_{\mathrm{s}}-h_{5}\right) \leq \mathrm{THS} 1\right) \\
\left(h_{5} \neq \mathrm{NaN}\right) \text { and }\left(h_{6} \neq \mathrm{NaN}\right) \\
\left(\operatorname{sgn}\left(h_{\mathrm{s}}-h_{5}\right)=-1\right) \text { and }(S=-1) \\
\left(\operatorname{sgn}\left(h_{\mathrm{s}}-h_{5}\right)=1\right) \text { and }(S=1) \\
\left(\operatorname{abs}\left(h_{\mathrm{s}}-h_{5}\right) \leq 1\right) \text { and }\left(t_{\mathrm{s}}-t_{5}>\mathrm{THD} 1\right) \\
\left(\operatorname{abs}\left(h_{\mathrm{s}}-h_{5}\right) \leq 2\right) \text { and }\left(t_{\mathrm{s}}-t_{5}>\mathrm{THD} 2\right) \\
\left(\operatorname{sgn}\left(h_{6}-h_{5}\right)=S\right) \text { and }\left(\operatorname{abs}\left(h_{6}-h_{5}\right) \geq \mathrm{THS} 2\right) \text { and } \\
\left(\operatorname{abs}\left(h_{\mathrm{s}}-h_{5}\right) \leq \mathrm{THS} 3\right) \\
\left(\operatorname{abs}\left(h_{\mathrm{s}}-h_{2}\right) \leq \mathrm{THS} 3\right) \text { and }\left(\operatorname{abs}\left(h_{\mathrm{s}}-h_{3}\right) \leq \mathrm{THS} 3\right) \text { and } \\
\left(\operatorname{abs}\left(h_{\mathrm{s}}-h_{4}\right) \leq \mathrm{THS} 3\right) \text { and }\left(\operatorname{abs}\left(h_{\mathrm{s}}-h_{5}\right) \leq \mathrm{THS} 3\right) \\
\left(t_{\mathrm{g}}>\mathrm{THD} 1\right) \text { and }\left(\operatorname{abs}\left(h_{\mathrm{s}}-h_{5}\right)<\mathrm{THS} 4\right)\end{array}$ & $\begin{array}{l}\text { THD1 } \\
\text { THD2 } \\
\text { THS2 } \\
\text { THS3 }\end{array}$ & $\begin{array}{l}10 \text { points } \\
20 \text { points } \\
3 \mathrm{~cm} \\
5 \mathrm{~cm}\end{array}$ \\
\hline
\end{tabular}

or not. In other words, point 5 is designated as an outlier if the data within the moving window satisfy one of the starting conditions. For example, as shown in Fig. 4a, if the difference between $h_{2}$ and $h_{5}$ exceeds a given threshold TH2 (i.e., $h_{2}-h_{5}>\mathrm{TH} 2$ ), then the target point (point 5 ) is considered as an outlier. The information of the target point ( $\operatorname{sign} S$, wave height $h_{\mathrm{s}}$, and its timing $t_{\mathrm{s}}$ ), which will be used in the end mode, is stored in memory. The sign $S$ is based on a sign function of a real number $x$ and can be expressed as

$\operatorname{sgn}(x)= \begin{cases}-1 & \text { if } x<0 \\ 0 & \text { if } x=0, \\ 1 & \text { if } x>0\end{cases}$

The total starting conditions and thresholds are listed in Table 1 . The backgrounds and the details of each condition are described below. One common problem in the start mode is the presence of gaps in the data stream because the difference in wave height between neighboring points can not be calculated if a gap exists. For example, if point 3 is a gap, the difference in wave height between point 5 and point 3 can not be obtained. In order to deal with gaps, the start mode stores a wave height $\left(h_{\mathrm{g}}\right)$ of one point before the target point and counts the length of gaps $\left(t_{\mathrm{g}}\right)$ whenever the target point meets a gap (Fig. 4a). Also, the starting conditions are divided into two categories depending on whether point 6 , one point before the target point, is a gap or not. SIF1 is the condition where point 6 is a gap, while SIF2 is the condition where point 6 is not a gap. For SIF1, to catch an outlier that starts right after the gaps, the target point (point 5) is designated as an outlier if the absolute value of the difference between $h_{5}$ and $h_{\mathrm{g}}$ exceeds a given threshold THh (called S01). For SIF2, the target point is designated as an outlier if the difference between $h_{5}$ and the wave heights of the other points from point 0 to point 4 exceeds a given threshold assigned depending on not only the distance between points but also the sign of the water level change. TH0, TH1, TH2, TH3, and TH4 are the thresholds for cases in which the sign of the difference between $h_{5}$ and the wave heights of the other points from point 0 to point 4 is a positive number (plus sign) or zero. By contrast, TH_0, TH_1, TH_2, TH_3, and TH_4 are the thresholds for the cases in which the sign of difference is a negative number (minus sign). The corresponding conditions are called S02-S11. In summary, the start mode designates the target point as an outlier and is changed to the keep mode if one of the starting conditions (S01-S11) is satisfied. 
(a) Start mode

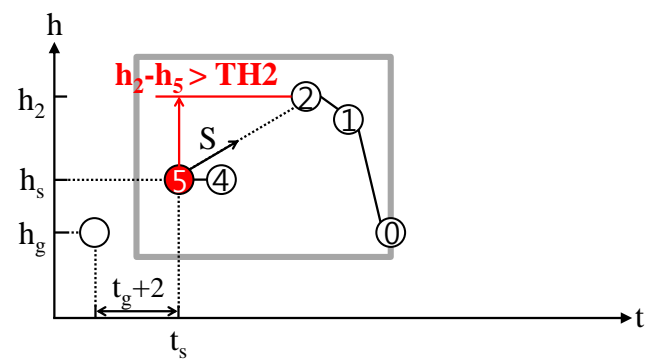

(b) Keep mode

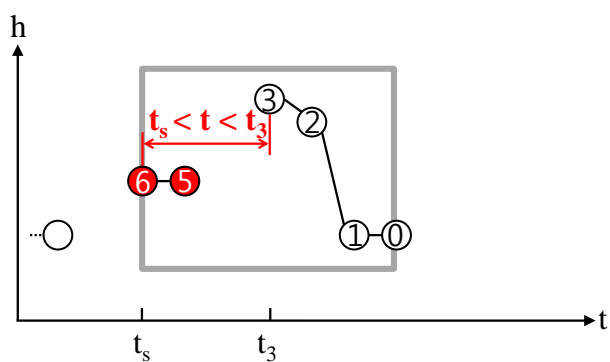

(c) End mode

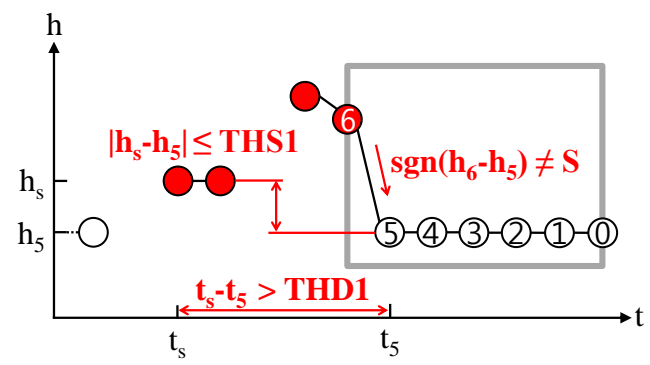

Figure 4. Schematic sketch of each mode of the outlier removal algorithm: (a) start mode, (b) keep mode, (c) end mode. The water level data are represented as circles, and a gray box indicates the moving window. Red circles indicate detected outliers, and conditions are written in red.

\subsubsection{Keep mode}

The intermediate points between two points triggered at start mode are always outliers. Thus, the keep mode obviates the unnecessary procedure of the start mode to determine whether the target point is an outlier or not for the intermediate points. The outlier removal algorithm keeps the keep mode for a certain time step depending on the thresholds that were triggered at the start mode: no time step for THh, TH4, or TH_4; one-time step for TH3 and TH_3; two-time step for TH2 and TH_2; three-time step for TH1 and TH_1; four-time step for TH0 and TH_0. For example, as shown in Fig. 4a, if point 5 was designated as an outlier because the difference between $h_{2}$ and $h_{5}$ exceeded TH2 (i.e., $h_{2}-h_{5}>$ TH2) at the start mode, then the intermediate points, point 3 and point 4 in Fig. 4a (which became point 4 and point 5 in Fig. 4b) were designated as outliers at the keep mode. In other words, the outlier removal algorithm keeps removing the data for a twotime step (because the outlier was designated by TH2) and then changes the mode to the end mode.

\subsubsection{End mode}

The end mode continues to remove the data until satisfying one of the ending conditions combined with sub-conditions, which is related to wave height, sign, and time span. For example, as shown in Fig. 4c, the ending conditions are combinations of several sub-conditions such as the water level retreating back to normal (e.g., $\left|h_{\mathrm{s}}-h_{5}\right| \leq$ THS1), the slope of the water level changing (e.g., $\operatorname{sgn}\left(h_{6}-h_{5}\right) \neq S$ ), or quite a long time passing by (e.g., $t_{\mathrm{s}}-t_{5}>$ THD1).

The total ending conditions and the thresholds are listed in Table 1. The backgrounds and the details of each condition are described below. Similar to the start mode, one common problem of the end mode is the presence of gaps in the data stream. In order to deal with gaps, the ending conditions divide into three categories depending on whether point 5 and point 6 are a gap or not. EIF1 is the condition where point 5 is a gap, EIF2 is the condition where point 5 should not be a gap and only point 6 is a gap, and EIF3 is the condition where neither point 5 nor point 6 is a gap. For EIF1, if not only the sign is reversed with $S\left(\operatorname{sgn}\left(h_{4}-h_{6}\right) \neq S\right.$ or 0 ) but the water level also retreats back to the normal water level $\left(\operatorname{abs}\left(h_{\mathrm{s}}-h_{6}\right) \leq\right.$ THS1), then the algorithm stops removing the data (called E01). For EIF2, since point 5 is not a gap any more, a similar condition with E01 $\left(\operatorname{sgn}\left(h_{4}-h_{5}\right) \neq S\right.$ or 0 and $\operatorname{abs}\left(h_{\mathrm{s}}-h_{5}\right) \leq$ THS1) is applied where point 5 is used instead of point 6 (called E02). For EIF3, the end mode stops if the sign is reversed from negative to positive $\left(\left(\operatorname{sgn}\left(h_{\mathrm{s}}-\right.\right.\right.$ $\left.\left.h_{5}\right)=-1\right)$ and $\left.(S=-1)\right)$ or vice versa $\left(\left(\operatorname{sgn}\left(h_{\mathrm{s}}-h_{5}\right)=1\right)\right.$ and $(S=1)$, and these conditions are called E03 and E04, respectively. Also, the end mode stops if a certain time passes $\left(t_{\mathrm{s}}-t_{5}>\right.$ THD1 $)$ and the water level retreats back to the normal water level $\left(\operatorname{abs}\left(h_{\mathrm{s}}-h_{5}\right) \leq 1\right)$, and this condition is called E05. If quite a long time passes $\left(t_{\mathrm{s}}-t_{5}>\mathrm{THD} 2\right)$, more relaxed condition $\left(\operatorname{abs}\left(h_{\mathrm{s}}-h_{5}\right) \leq 2\right)$ than E05 is applied and this condition is called E06. Another ending condition is required to deal with long outliers because of the tide that changes the mean water level. In other words, the end point of long outliers within flood tide or ebb tide would not retreat back to the normal water level. Thus, in order to deal with long outliers, two ending conditions are introduced. One way is to stop the end mode if the sign is reversed with $S\left(\operatorname{sgn}\left(h_{6}-h_{5}\right)=S\right)$ and the water level changes abruptly $\left(\operatorname{abs}\left(h_{6}-h_{5}\right) \geq\right.$ THS2), even though water level does not retreat back to the normal water level yet $\left(\operatorname{abs}\left(h_{\mathrm{s}}-h_{5}\right) \leq \mathrm{THS} 3\right)$, and this condition is called E07. Another way is to stop the end mode if all four consecutive water levels do not retreat back to normal but are under a certain range (called E08). In order to deal with long gaps, if the outlier starts after long gaps $\left(t_{\mathrm{g}}>\right.$ THD1) and the water level retreats back to normal $\left(\operatorname{abs}\left(h_{\mathrm{s}}-h_{5}\right)<\right.$ THS4), the end mode stops and this condition is called E09. In summary, the 
Table 2. Parameters of a gap-filling algorithm.

\begin{tabular}{|c|c|c|c|}
\hline Algorithm & Parameter & Value & Description \\
\hline & $n_{\text {LGFA }}$ & $4 \mathrm{~h}$ & Standard gap size whether applying SGFA or LGFA \\
\hline SGFA & N_inter & 2 points & Number of points from the last point before the gap \\
\hline LGFA & $\begin{array}{l}m v_{\mathrm{LGFA}} \\
\text { windowsize } \\
\text { npastdata }\end{array}$ & $\begin{array}{l}10 \min \\
2 \\
100\end{array}$ & $\begin{array}{l}\text { Time interval that is used to calculate the moving-averaged data } \\
\text { Factor to determine the size of target window } \\
\text { Factor to determine the size of past dataset, } m_{\text {search }}\end{array}$ \\
\hline
\end{tabular}

end mode stops removing the data and reverts to start mode if one of the ending conditions (E01-E09) is satisfied.

\subsection{Gap-filling algorithm}

Because the gap-filling algorithm is activated after the outlier removal algorithm, the gaps of the original data and the outliers removed by the outlier removal algorithm are subject to the gap-filling algorithm. The first step is to count the gap size $n_{\text {Gap }}$. Whenever a gap ends, the gap-filling algorithm performs one of the sub-algorithms (SGFA and LGFA) depending on predefined criterion $n_{\text {LGFA }}$ (Table 2). If the gap exists but its size is smaller than $n_{\text {LGFA }}$, the SGFA is applied. If the gap size is greater than or equal to $n_{\text {LGFA }}$, the LGFA is applied. The full process of sub-algorithms and parameters is described below.

\subsubsection{SGFA (Short Gap-Filling Algorithm)}

Depending on gap sizes, the SGFA is again divided into two categories: one point gap and short gaps (Fig. 5). For one point gap, the gap is replaced by the wave height just before the gap $\left(h\left(t_{\text {gap }}\right)=h\left(t_{\text {gap }}-1\right)\right)$, where $t_{\text {gap }}$ is the time of the gap. For short gaps $\left(1<n_{\text {Gap }}<n_{\text {LGFA }}\right)$, linear interpolation is applied to fill the gap. If we use only one point for the linear interpolation, the results do not fit well because of a temporary water level fluctuation just before short gaps. Thus, the number of points before short gaps (N_inter) is used for the linear interpolation (Table 2).

\subsubsection{LGFA (Long Gap-Filling Algorithm)}

The LGFA is divided into three steps (Fig. 6). The first step is to filter out background noise by applying a MAF (moving average filter) on a window of length $m v_{\text {LGFA }}$ (Fig. 6a and Table 2) and define a target window, which consists of the gaps, the boundary points EP1 and EP2, and target data. EP1 is the end point just before where gaps start, while EP2 is the end point just after where gaps end. The target data are the data just before the gap and they will be used to look for the data suitable for filling the gap in the next step. The size of the target window is proportional to the gap size (windowsize $\left.\times\left(n_{\text {Gap }}+2\right)\right)$, where windowsize is a factor that determines the size of the window (Table 2). (a) One point gap

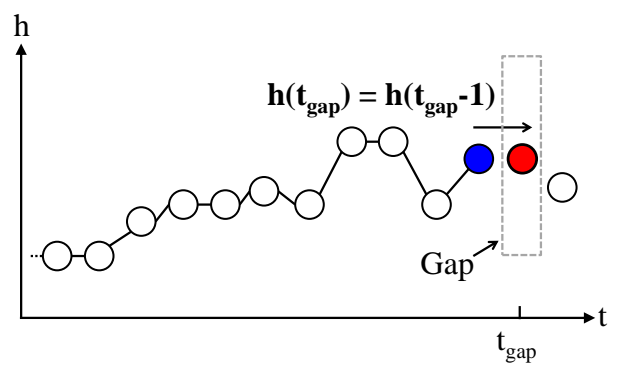

(b) Short gaps

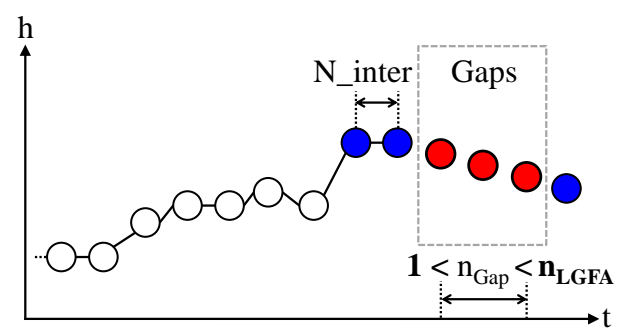

Figure 5. Schematic sketch of SGFA of the gap-filling algorithm: (a) one point gap, (b) short gaps. The water level data are represented as circles, and a gray dotted box indicates the location of gaps. Blue circles indicate the data used to fill the gaps and red circles indicate gap-filled data.

The second step is to find the most suitable data to fill the gaps (Fig. 6b). The LGFA hypothesizes that the gaps will follow the trend of the past water level movement. Thus, the most suitable data for gaps are the data that show the most similar trend with those of the target data. In order to find the most suitable data, search window and search data are set to the same size as the target window and the target data, respectively. The MAE (mean absolute error) between the target data and the search data is calculated while the search window moves back over the length of $m_{\text {search from the EP1. }}$ The $m_{\text {search }}$ is proportional to the size of the target window (npastdata $\times$ windowsize $\left.\times\left(n_{\text {Gap }}+2\right)\right)$, where npastdata is a factor. The search window that shows minimum MAE is selected for gap filling (Table 2).

The last step is to fill the gaps (Fig. 6c). The SW (search window) data, which are the remaining data of the search 
(a) Target window

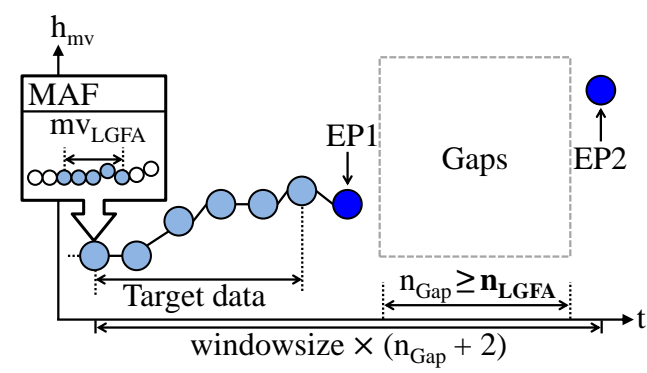

(b) Search window

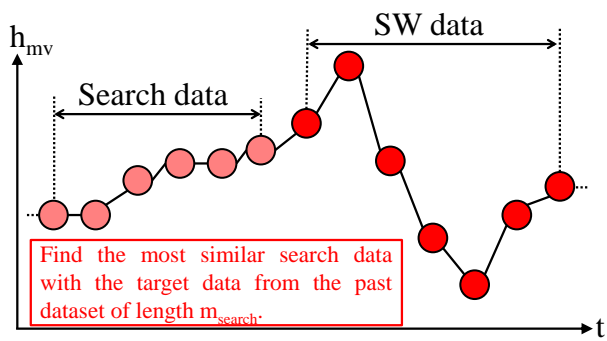

(c) End-point fixing method

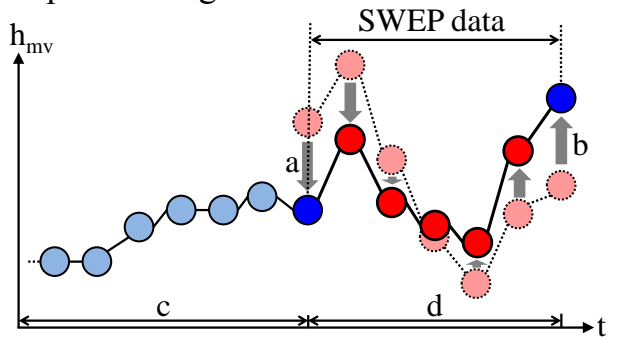

Figure 6. Schematic sketch of LGFA of the gap-filling algorithm: (a) target window (blue tone), (b) search window (red tone), (c) endpoint fixing method. The water level data are represented as circles, and a gray dotted box indicates the location of gaps. MAF stands for moving average filter. The moving-averaged data are referred to as $h_{\mathrm{mv}}$.

window after concealing the search data, are rebalanced by the EPFM (end-point fixing method) to keep the continuity of the time series. The EPFM fixes the first and last points of SW data to the EP1 and EP2 and linearly balances the intermediate data using the following equation:

$H_{\mathrm{EP}}(t)=H_{\mathrm{ori}}(t)+\frac{b-a}{d}(t-c)+a$ for $c \leq t \leq c+d$,

where $H_{\mathrm{EP}}(t)$ is the water level after the EPFM is applied (red circle in Fig. 6c), $H_{\text {ori }}(t)$ is the water level before the EPFM is applied (translucent red circle in Fig. 6c), $a$ is the difference between the start point of SW data and EP1, $b$ is the difference between the end point of SW data and EP2, $c$ is the time of the start point of SW data, and $d$ is the time span of SW data. Finally, the resulting data, called SWEP (search window end-point fixed) data, replace the gaps.

\subsection{Tsunami detection algorithm}

The tsunami detection algorithm performs three parallel subalgorithms, denoted by DART, SLOPE, and TIDE, during every new data acquisition. There are four total thresholds: $\mathrm{TH}_{\text {DART }}$ for DART, $\mathrm{TH}_{\mathrm{IS}}$ and $\mathrm{TH}_{\mathrm{CF}}$ for SLOPE, and $\mathrm{TH}_{\mathrm{TIDE}}$ for TIDE. If any kind of threshold is triggered, the TDI is counted in increments of one and lasts for a time interval $t_{\text {detect }}$. Thus, the TDI ranges from zero (all thresholds are not triggered) to four (all thresholds are triggered). The higher the TDI is, the more likely a tsunami is detected. When the TDI is equal to 4 , a warning alarm (red) is activated; when the TDI is equal to 3 , an advisory alarm (orange) is activated; finally, when the TDI is equal to 2 or 1 , a watch alarm (yellow) is activated. The full process of subalgorithms and parameters is described below.

\subsubsection{DART}

The DART is an amplitude-based algorithm that uses a cubic polynomial fit to predict the water level (Fig. 7a). The predicted water level can be obtained by a cubic polynomial fit to the data stored over the preceding $3 \mathrm{~h}$ and $10 \mathrm{~min}$ and can be expressed as

$h_{\mathrm{DART}}(t)=\sum_{i=0}^{3} \omega_{i} \overline{h_{i}}\left(t-1-\frac{300}{\Delta t}-i \frac{3600}{\Delta t}\right)$,

where $h_{\text {DART }}$ is the predicted water level, $\bar{h}$ is the $10 \mathrm{~min}$ average of the measured water level, $\Delta t$ is a sampling interval expressed in seconds, and $\omega_{i}$ are the coefficients calculated by applying Newton's forward divided difference formula (Mofjeld, 1997). The DART index (DI) is defined as the absolute value of the difference between the measured water level and the predicted water level $\left(\mathrm{DI}(t)=\left|h(t)-h_{\mathrm{DART}}(t)\right|\right)$. The DART assumes that tsunami detection occurs when the DI surpasses the threshold:

$\mathrm{DI}\left(t_{\text {now }}\right) \geq \mathrm{TH}_{\text {DART }}$.

\subsubsection{SLOPE}

The SLOPE is a slope-based algorithm designed to detect a tsunami with an impulsive front (Fig. 7b). Using the same terminology as Bressan and Tinti (2011), the average slope $\mathrm{IS}_{T}(t)$ is calculated by a least square fitting over the time interval $\mathrm{I}_{\mathrm{IS}}(t)$ of length $t_{\mathrm{IS}}$. The Tide uns $(t)$ is the average $\operatorname{IS}_{T}(t)$ over time interval $I_{\text {Tide }}(t)$ of length $t_{\text {GTide }}$ going back from the past time $t_{\text {GTide }}$. The tide slope estimation Tide $(\mathrm{t})$ is calculated by averaging the $\operatorname{Tide}_{\text {uns }}(t)$ over an interval length $t_{\mathrm{sm}}$. Now, the detided instantaneous slope IS $(t)$ could be obtained by subtracting the tide slope estimation from the average slope $\left(\operatorname{IS}(t)=\operatorname{IS}_{T}(t)-\right.$ Tide $\left.(t)\right)$. The background slope $\mathrm{BS}(t)$ is calculated by Eq. (5) over time interval $I_{\mathrm{BS}}(t)$ of length $t_{\mathrm{BS}}$ going back from the past time $t_{\mathrm{g}}$. 
(a) DART

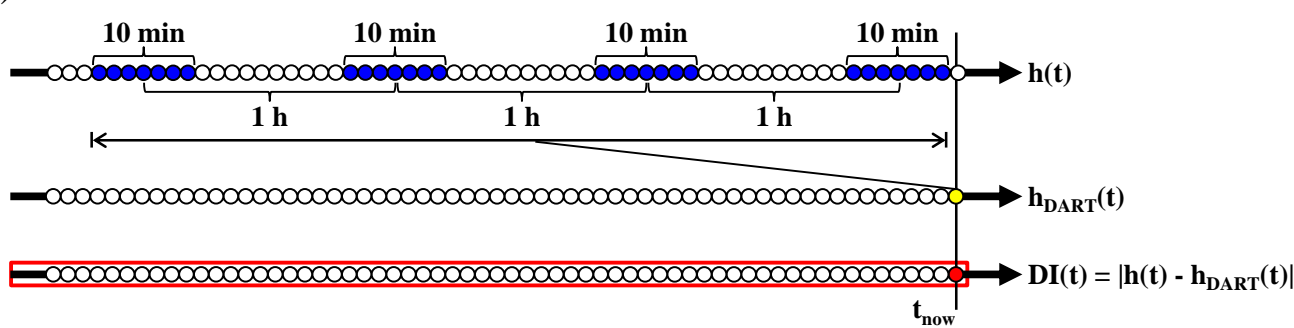

(b) SLOPE

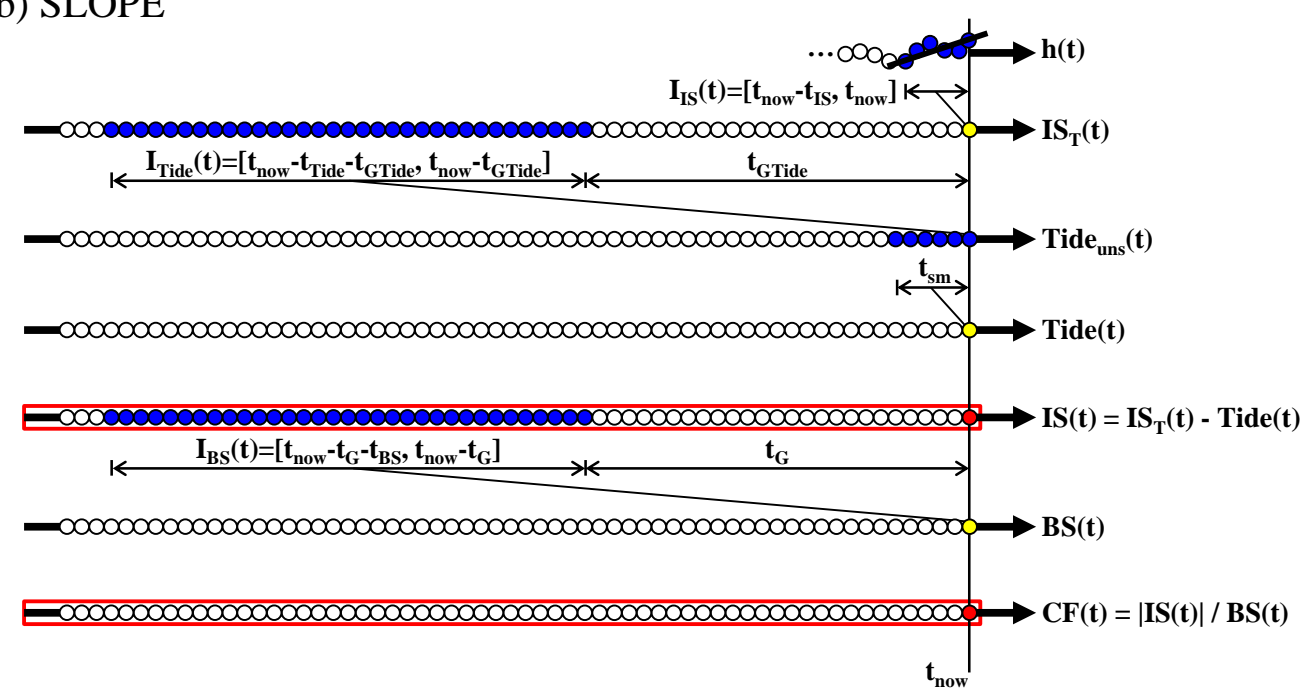

(c) TIDE

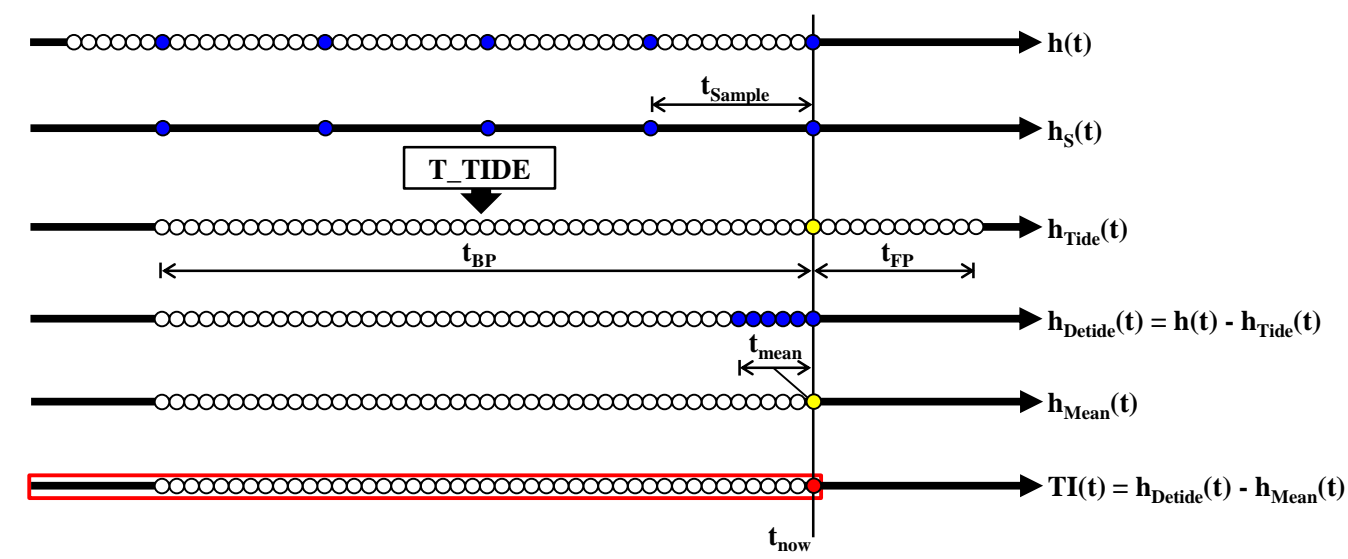

Figure 7. Schematic sketch of the tsunami detection algorithm: (a) DART, (b) SLOPE, (c) TIDE. From top to bottom panels: the procedures of how the indexes, DI, IS, CF, and TI (red boxes), are calculated from the water level data. Each index (red circle) is calculated using the past data (blue circles) and the intermediate outputs (yellow circles) whenever new data are acquired.

$\mathrm{BS}(t)=\operatorname{standard}$ deviation of $\mathrm{IS}\left(t^{\prime}\right) \cdot \sqrt{2} ; t^{\prime} \in I_{\mathrm{BS}}$

Finally, we could get the control function $\mathrm{CF}(t)$, which is a ratio of the absolute value of the detided instantaneous slope to the background slope $(\mathrm{CF}(t)=|\mathrm{IS}(t)| / \mathrm{BS}(t))$. The SLOPE assumes that tsunami detection occurs when the absolute values of the detided instantaneous slope and the control function surpasses the thresholds, respectively: 
$\left|\mathrm{IS}\left(t_{\text {now }}\right)\right| \geq \mathrm{TH}_{\mathrm{IS}}$

$\mathrm{CF}\left(t_{\text {now }}\right) \geq \mathrm{TH}_{\mathrm{CF}}$.

\subsubsection{TIDE}

The TIDE is an amplitude-based algorithm that uses a harmonic analysis (Fig. 7c). The sampled data $h_{\mathrm{s}}(t)$ are collected from the water level data $h(t)$ regularly spaced at a sampling interval $t_{\text {sample }}$ over the preceding time $t_{\mathrm{BP}}$. When the event period starts, the T_TIDE is activated to predict the tide data $h_{\text {Tide }}(t)$ over the period $t_{\mathrm{BP}}+t_{\mathrm{FP}}$. The T_TIDE is a classical harmonic analysis program that evaluates the tidal constituents (frequency, amplitude, phase, etc.). A detailed description can be found in Pawlowicz et al. (2002). The detided water level data $h_{\text {Detide }}(t)$ are obtained by subtracting the tide data from the water level data $\left(h_{\text {Detide }}(t)=h(t)-h_{\text {Tide }}(t)\right)$. The average detided data $h_{\text {Mean }}(t)$ over the time interval $t_{\text {mean }}$, which starts from the most recent data, are then obtained. The tide index (TI) is defined as the difference between the detided water level and the mean water level $\left(\operatorname{TI}(t)=h_{\text {Detide }}(t)-h_{\text {Mean }}(t)\right)$. The TIDE assumes that tsunami detection occurs when the absolute value of TI surpasses the threshold:

$\left|\mathrm{TI}\left(t_{\text {now }}\right)\right| \geq \mathrm{TH}_{\mathrm{TIDE}}$.

\section{Calibration of TADS}

In order to calibrate the TADS, the water level data of the Ulleung-do surge gauge recorded from 1 to 31 March 2011 were employed. After calibrating several parameters and thresholds of algorithms, the event period, which starts when an earthquake occurs and lasts until a tsunami sufficiently passes by, was set to $8 \mathrm{~h}$ after the 2011 Tōhoku earthquake based on the results of a numerical simulation (Lee et al., 2015).

\subsection{Calibration of outlier removal algorithm}

Since several equivocal outliers are hardly distinguishable, we used the tide estimation predicted by the T_TIDE to calibrate the outlier removal algorithm. After setting the thresholds of the outlier removal algorithm to arbitrary values, we compared the outlier's removed data with the tide estimation. Whenever the outlier removal algorithm failed to remove the data, which showed a large discrepancy between the water level data and the tide estimation, we modulated the thresholds. Conversely, whenever the outlier removal algorithm removed the data, which showed a small discrepancy between the water level data and the tide estimation, we also modulated the thresholds. The abovementioned process was repeated until the thresholds converged to a certain value. The resulting values of thresholds are listed in Table 1.
Table 3. Examples of a gap-filling algorithm. The information of window and the mean absolute error (MAE) between the predicted data and measured data are listed.

\begin{tabular}{|c|c|c|c|}
\hline \multirow{2}{*}{$\begin{array}{l}\text { Gap } \\
\text { size } \\
\text { (h) }\end{array}$} & \multicolumn{2}{|c|}{ Time of starting point (LT) } & MAE \\
\hline & Target window & Search window & \\
\hline 3 & 31 Mar 2011 05:31:10 & 20 Mar 2011 07:26:20 & 0.58 \\
\hline 12 & 21 Mar 2011 21:07:10 & 19 Mar 2011 07:55:10 & 2.08 \\
\hline 24 & 17 Mar 2011 15:21:40 & 3 Mar 2011 16:19:10 & 3.22 \\
\hline 36 & 21 Mar 2011 15:36:00 & 18 Mar 2011 01:26:20 & 4.56 \\
\hline
\end{tabular}

Figure 8 shows nine examples of results obtained using the outlier removal algorithm based on the calibrated thresholds. Figure 8a shows a case in which two types of outliers are clearly detected: one that slowly increases and gradually decreases and another that sharply increases and suddenly decreases. Figure $8 \mathrm{~b}$ and $\mathrm{c}$ show cases in which the longterm outliers that offset the data are also perfectly detected. Figure $8 \mathrm{~d}$ and $\mathrm{h}$ present cases in which the long-term outliers with gaps are clearly detected, which allows the algorithm to manage the missing data. Figure 8e shows the double outliers. Here, the second outliers appear immediately after the first outliers. Figure $8 \mathrm{f}$ shows the meteorological outliers when a wind wave advisory was in effect for the far East Sea. Figure $8 \mathrm{~g}$ presents a case in which approximately 10 min of gaps exist in the data stream. It should be noted that the point immediately after a gap is classified as normal. Figure $8 \mathrm{i}$ shows the instantaneously oscillating outliers that maintain for approximately $10 \mathrm{~min}$. We should focus on the points classified as normal among outliers in Fig. 8a, e, and i that prevent long-term gaps because the performance of the gap-filling algorithm (which will be explained later) is in inversely proportional to the gap size.

\subsection{Calibration of gap-filling algorithm}

After calibrating the thresholds of the outlier removal algorithm, we calibrated the parameters of the gap-filling algorithm that ensure the best performance for the Ulleung-do surge gauge data (Table 2). The N_inter, which is the number of points for linear interpolation, was set to two points for two reasons: one point was insufficient to prevent the slope distortion provoked by temporary water level fluctuation, while a value greater than two points did not show notably different performance. To calibrate the remaining parameters, we intentionally omitted water levels in some periods and ran the gap-filling algorithm to predict the gaps, which were intentionally omitted. Then, the predicted water levels of gaps and the water level data that were intentionally omitted were compared. The abovementioned process was repeated until the algorithm ensured the best performance where the MAE between the intentionally omitted data and 

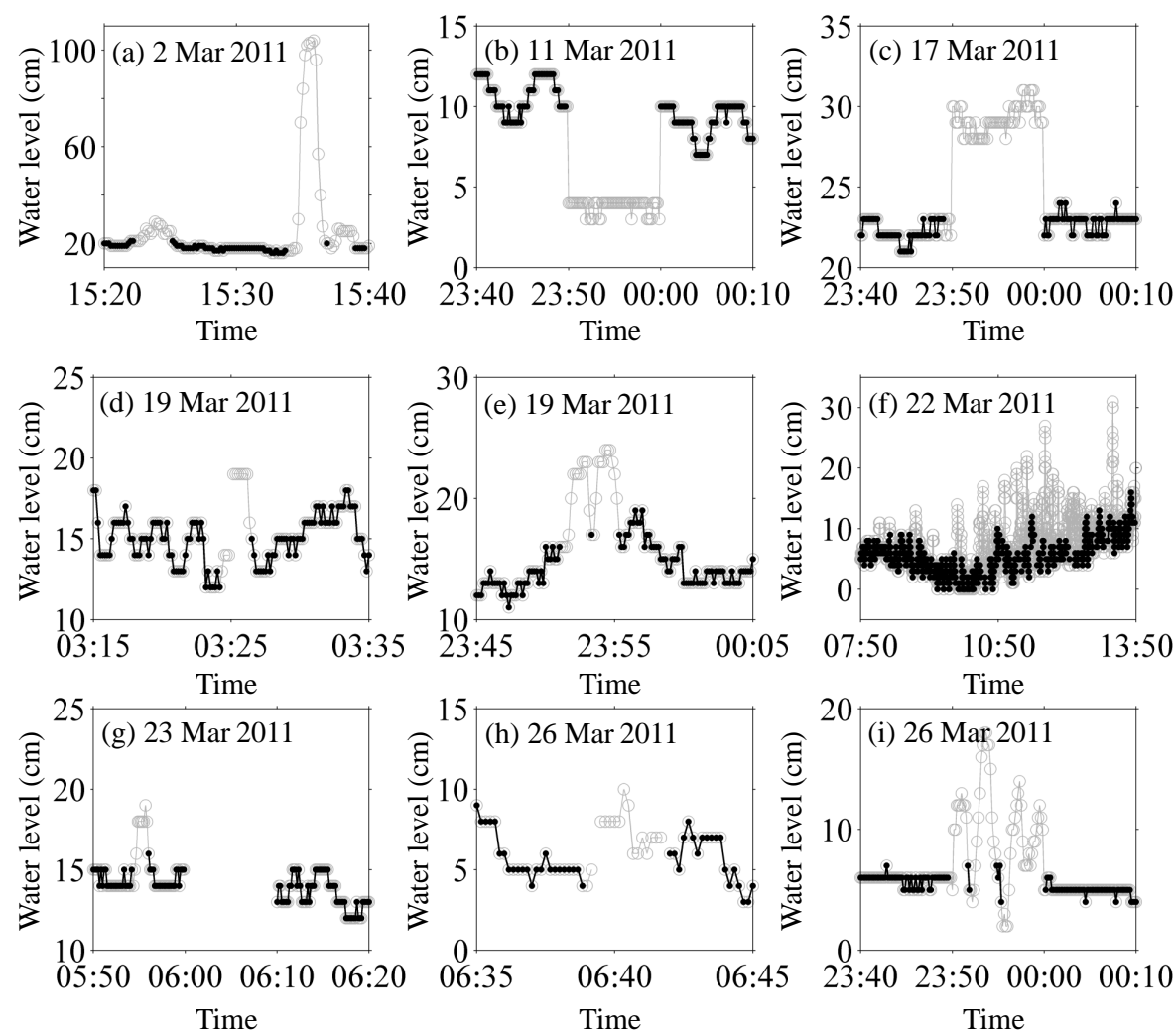

Figure 8. Examples of an outlier removal algorithm using calibrated thresholds. The gray line with a circle represents the original data, and the black line with a circle represents the outlier-removed data.

the predicted data showed the smallest value. We considered 34 cases of gap sizes from 3 to $36 \mathrm{~h}$ with $1 \mathrm{~h}$ intervals, and 31 datasets from 12 to 29 March 2011 with 50000 s intervals. Finally, criterion $n_{\text {LGFA }}$, the standard gap size to decide whether to apply SGFA or LGFA, was set to be $4 \mathrm{~h}$, which is the maximum value within the boundary where the same performance between SGFA and LGFA is guaranteed.

Figure 9 shows four examples of the results obtained with the LGFA. Table 3 provides the information of window and the MAE between predicted data and measured data for those four examples. After selecting the data of search window (gray line), which shows the most similar trends with those of the target data (black line), the SWEP data (blue line) were compared with the data intentionally omitted (red line). It should be noted that the EPFM improves the accuracy of prediction in most cases. For example, Fig. 9a and b show cases in which the target data and the search data are similar but the SW data are not fit with the data intentionally omitted. Because the EPFM enforces the end point of the SW data to match the end point of the measured data, the SWEP data show a good agreement with the data intentionally omitted. However, as shown in Fig. 9c and d, the EPFM is less effective for the cases in which the end point of the SW data is similar to that of the data intentionally omitted. We should note that even though comparatively lower accuracy is ob- tained as the gap size increases, because the longest gaps of the Ulleung-do surge gauge between 1 and 31 March are approximately $6 \mathrm{~h}$, the LGFA performs reliably in alleviating the gap-filling problem.

\subsection{Calibration of tsunami detection algorithm}

The parameters of the tsunami detection algorithm are listed in Table 4. The parameters of DART were calculated by applying Newton's forward divided difference formula for the case of $10 \mathrm{~s}$ interval data of the Ulleung-do surge gauge. The parameters of SLOPE were set to the same values of Bressan and Tinti (2011), which were tested with a sufficient number of samples. The parameters of TIDE were set to the values as the total computing time allows. For example, the sampling interval $t_{\text {sample }}$ was set to $1 \mathrm{~min}$ to accelerate the calculation of harmonic analysis. Also, we assumed that the dataset of 10 days is enough for harmonic analysis ( $t_{\mathrm{BP}}=10$ days) and the tsunami would not last longer than 2 days $\left(t_{\mathrm{FP}}=2\right.$ days). Lastly, the averaging interval $t_{\text {mean }}$ was set to $1 \mathrm{~h}$ to filter out the high-frequency component.

After fixing the parameters, the thresholds of the tsunami detection algorithm were calibrated based on the record of the 2011 Tōhoku tsunami. Since there is no absolute standard of the tsunami's arrival time, the thresholds should compro- 
(a) Gap size $=3 \mathrm{~h}$
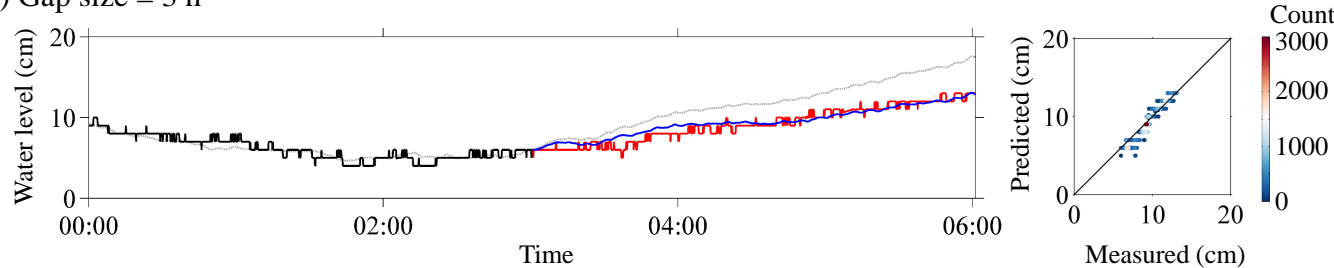

(b) Gap size $=12 \mathrm{~h}$
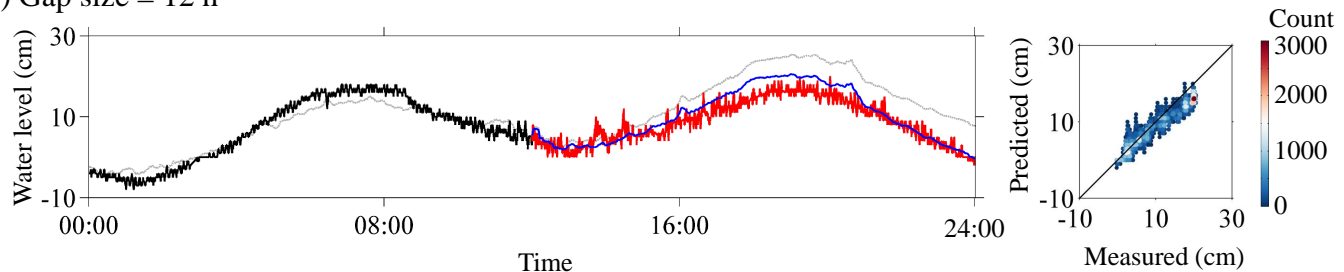

(c) Gap size $=24 \mathrm{~h}$
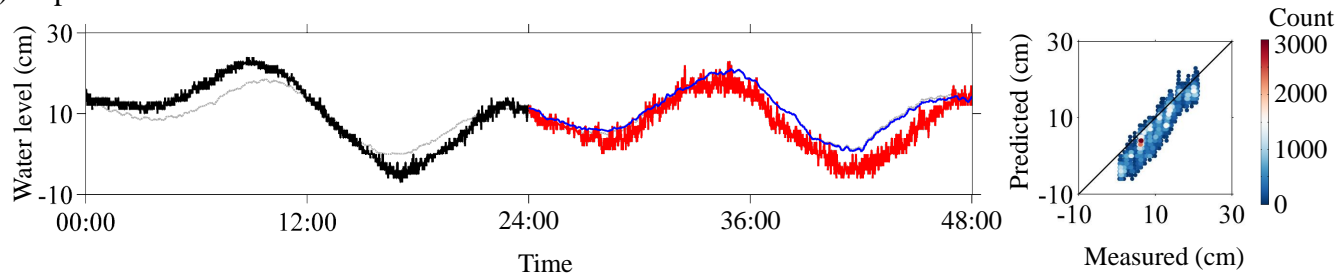

(d) Gap size $=36 \mathrm{~h}$
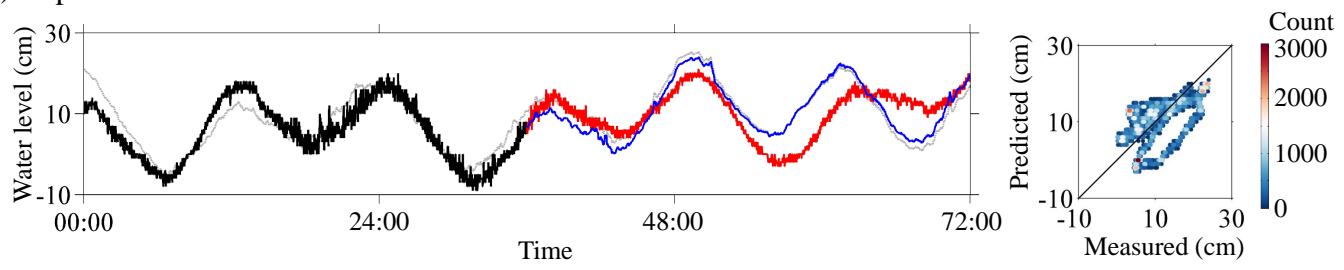

Figure 9. Examples of the gap-filling algorithm using the calibrated parameters when the gap sizes are (a) $3 \mathrm{~h}$, (b) $12 \mathrm{~h}$, (c) $24 \mathrm{~h}$, and (d) $36 \mathrm{~h}$. The left panel shows the time series. The black lines represent the target data, and the gray lines represent the data of the selected search window. Blue lines represent the SWEP data; red lines represent the measured data that were intentionally omitted. The right panel shows the scatter plot between the predicted data (or the SWEP data) and the measured data. The color point represents the frequency of data plotted inside the circle with a radius of $1 \mathrm{~cm}$.

mise with preciseness. As the thresholds are set to large values, the rate of false alarm would decrease while the rate of miss would increase, and vice versa. Thus, after setting the thresholds to arbitrary values, we modulated the thresholds within the range of values that do not cause any false alarm or miss the alarm by visual inspection.

Figure 10 shows the part of the calibration process of the tsunami detection algorithm. For the sake of simplicity, the threshold configuration $\left(\mathrm{TH}_{\mathrm{DART}}=5 \mathrm{~cm}\right.$, $\left.\mathrm{TH}_{\mathrm{IS}}=0.01 \mathrm{~cm} \mathrm{~s}^{-1}, \mathrm{TH}_{\mathrm{CF}}=4, \mathrm{TH}_{\mathrm{TIDE}}=5 \mathrm{~cm}\right)$ will be collectively referred to as one that is a standard value of the normalized threshold. As the normalized thresholds increase, all kinds of detection rates decrease and all kinds of start times of detection increase. The detection rate of CF becomes zero when the normalized threshold is greater than 1.34 (Fig. 10b). For that reason, the warning alarm disappears when the normalized threshold is greater than 1.34 (Fig. 10d). Even though both IS and CF derive from the
SLOPE, the detection rate of CF yields more sensitive results than the detection rate of IS does. By contrast, two amplitude-based algorithms (DART and TIDE) show similar patterns of both detection rate and start time of detection. We should note that if the normalized threshold is set to less than 0.4 , one or more thresholds are triggered within $8 \mathrm{~min}$, which thus represents a false alarm (Fig. 10c). By contrast, if the normalized threshold is set to greater than 1.06, the start time of the warning alarm is $16 \mathrm{~min}$ or more, which is the moment when the steep fluctuation in the water level has already passed (Fig. 10e). Thus, to prevent both a false alarm and a missed alarm, the normalized threshold should be set in the range of 0.4 to 1.06 . In this study, we set the normalized threshold to one. 
Table 4. Parameters and thresholds of a tsunami detection algorithm.

\begin{tabular}{|c|c|c|c|}
\hline Algorithm & $\begin{array}{l}\text { Parameter/ } \\
\text { threshold }\end{array}$ & Value & Description \\
\hline \multirow[t]{5}{*}{ DART } & $\omega_{0}$ & 2.1957 & Coefficient calculated by Newton's forward divided difference formula \\
\hline & $\omega_{1}$ & -2.2038 & Coefficient calculated by Newton's forward divided difference formula \\
\hline & $\omega_{2}$ & 1.3233 & Coefficient calculated by Newton's forward divided difference formula \\
\hline & $\omega_{3}$ & -0.3152 & Coefficient calculated by Newton's forward divided difference formula \\
\hline & TH DART & $5 \mathrm{~cm}$ & Threshold for the detection condition of DART: DI $\left(t_{\text {now }}\right) \geq \mathrm{TH}_{\mathrm{DART}}$ \\
\hline \multirow[t]{8}{*}{ SLOPE } & $t_{\mathrm{IS}}$ & $10 \min$ & Time interval used to compute the instantaneous slope, $\operatorname{IS}_{T}(t)$ \\
\hline & $t_{\text {Tide }}$ & $1 \mathrm{~h}$ & Time interval used to compute the tide slope estimation, $\operatorname{Tide}_{\text {uns }}(t)$ \\
\hline & $t_{\text {GTide }}$ & $16 \mathrm{~min}$ & Gap time to make $\operatorname{Tide}_{\text {uns }}(t)$ independent from an incoming anomalous wave \\
\hline & $t_{\mathrm{sm}}$ & $6 \min$ & Time interval to reduce oscillations of the tidal slope due to long period waves \\
\hline & $t_{\mathrm{BS}}$ & $1 \mathrm{~h}$ & Time interval used to calculate the background slope signal, BS $(t)$ \\
\hline & $t_{\mathrm{g}}$ & $15 \mathrm{~min}$ & Delay time to reduce the correlation between $\operatorname{IS}(t)$ and $\mathrm{BS}(t)$ \\
\hline & $\mathrm{TH}_{\mathrm{IS}}$ & $0.01 \mathrm{~cm} \mathrm{~s}^{-1}$ & Threshold for the detection condition of SLOPE: $\left|\mathrm{IS}\left(t_{\text {now }}\right)\right| \geq \mathrm{TH}_{\mathrm{IS}}$ \\
\hline & $\mathrm{TH}_{\mathrm{CF}}$ & 4 & Threshold for the detection condition of SLOPE: $\mathrm{CF}\left(t_{\text {now }}\right) \geq \mathrm{TH}_{\mathrm{CF}}$ \\
\hline \multirow[t]{6}{*}{ TIDE } & $t_{\text {sample }}$ & $1 \mathrm{~min}$ & Sampling interval to compute the tide estimation, $h_{\text {Tide }}(t)$ \\
\hline & $t_{\mathrm{BP}}$ & 10 days & Time interval of past data used to compute the tide estimation, $h_{\text {Tide }}(t)$ \\
\hline & $t_{\mathrm{FP}}$ & 2 days & Time interval used to predict the tide estimation, $h_{\text {Tide }}(t)$ \\
\hline & $t_{\text {mean }}$ & $1 \mathrm{~h}$ & Time interval used to compute the average detided data, $h_{\text {Mean }}(t)$ \\
\hline & $\mathrm{TH}_{\mathrm{TIDE}}$ & $5 \mathrm{~cm}$ & Threshold for the detection condition of TIDE: $\left|\mathrm{TI}\left(t_{\text {now }}\right)\right| \geq \mathrm{TH}_{\mathrm{TIDE}}$ \\
\hline & $t_{\text {detect }}$ & $10 \mathrm{~min}$ & Duration time of detection \\
\hline
\end{tabular}

\section{Performance of TADS}

The performance of TADS was evaluated by using three types of data. First, the 2011 Tōhoku tsunami data of the Ulleung-do surge gauge were used to investigate the overall performance based on the real tsunami record. Second, the water level data of the Ulleung-do surge gauge recorded from 1 January 2011 to 31 December 2011 were used to investigate the performance of the outlier removal and gap-filling algorithms. Third, several synthetic tsunamis were used to demonstrate the performance of the tsunami detection.

\subsection{Tōhoku tsunami}

Figure 11 illustrates the comprehensive results of TADS based on the calibrated thresholds, where the application to the 2011 Tōhoku tsunami data of the Ulleung-do surge gauge is shown. Looking at the comprehensive results of TADS based on the calibrated thresholds, the outlier removal algorithm removes the outliers that appear a few minutes after the end of the event period. On the other hand, the abrupt water level change measured twice approximately $19 \mathrm{~h}$ after the 2011 Tōhoku earthquake was not designated as an outlier. For these reasons, all thresholds except $\mathrm{TH}_{\mathrm{CF}}$ were triggered for that moment outside the event period. However, we should note that the tsunami detection algorithm, which skips the alarm for the event period, prevents the occurrence of a false alarm.

The Ulleung-do surge gauge went offline on 10 March 2011 at 03:10:00 LT and restarted the recording on 10 March 2011 at 09:29:00 LT. Fortunately, the gaps were filled with the LGFA of the gap-filling algorithm immediately after the gauge restarted the recording. It should be noted that the tsunami detection algorithm might have missed the alarm without the gap-filling algorithm if the gauge had gone offline just before the 2011 Tōhoku earthquake.

There are warning alarms that appeared on 11 March 2011 at 14:58:30 LT (approximately $12 \mathrm{~min}$ after the 2011 Tōhoku earthquake struck) and remained for approximately $15 \mathrm{~min}$ (Fig. 11a). The watch alarm with an intermittent advisory alarm followed the warning alarm. If we recall that the arrival time, which can be recognized in the records by eye inspection, was about $8 \mathrm{~min}$ (Fig. 10), the delay time of the warning alarm was about $4 \mathrm{~min}$, which is quite acceptable for practical use.

Since the 2011 Tōhoku tsunami was a tsunami caused by an earthquake, the event period could be defined properly and the tsunami was well detected. However, tsunamis can result from submarine landslides, subaerial landslides, volcanic eruptions, atmospheric disturbances, asteroid and comet impacts, and man-made explosions (Pugh and Woodworth, 2014). Korea has experienced meteotsunamis in both 2007 and 2008, which engulfed a part of the western coast of the Korean Peninsula, causing two and nine casualties, respectively (Yoon et al., 2014). Thus, future studies should attempt to link the event period with the information related to landslides, volcanic activity, and atmospheric pressure to cope with several types of tsunamis. 

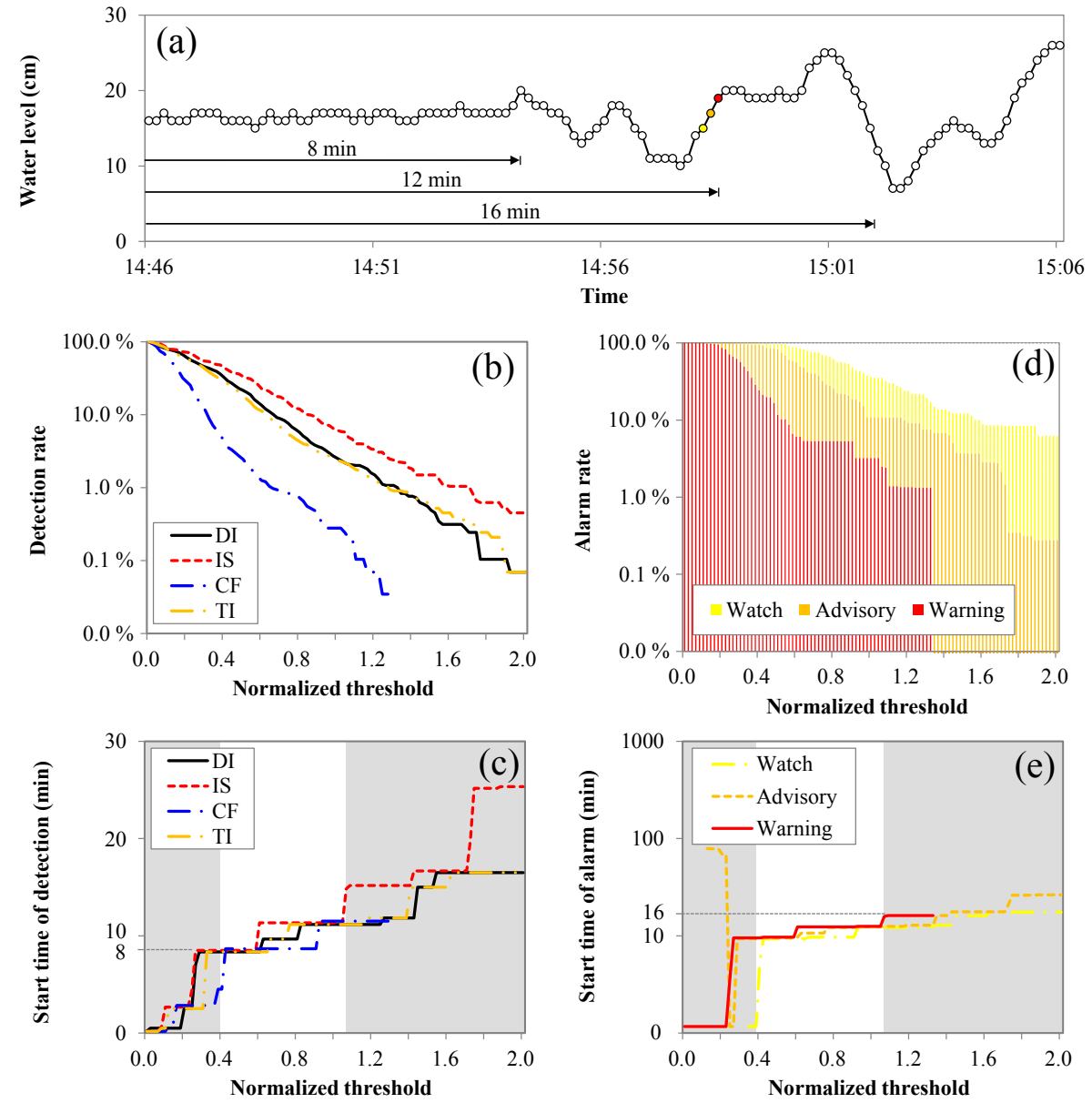

Figure 10. Examples of the tsunami detection algorithm using the calibrated parameters when the normalized threshold changes from zero to two with 0.02 intervals. (a) The 2011 Tōhoku tsunami recorded in the Ulleung-do surge gauge. The colored circle represents the start point of each alarm (red: warning, orange: advisory, yellow: watch) when the normalized threshold is set to one $\left(\mathrm{TH} \mathrm{DART}_{\mathrm{DA}}=5 \mathrm{~cm}\right.$, $\mathrm{TH}_{\mathrm{IS}}=0.01 \mathrm{~cm} \mathrm{~s}^{-1}, \mathrm{TH}_{\mathrm{CF}}=4, \mathrm{TH}_{\mathrm{TIDE}}=5 \mathrm{~cm}$ ). For each index (DI, IS, CF, and TI), (b) detection rate during the event period and $(\mathbf{c})$ start time of detection are given. For each alarm (warning, advisory, and watch), (d) alarm rate during the event period and (e) start time of alarm are given. The gray shade region marks the range of the normalized threshold where a false or missed alarm occurs.

\subsection{Performance of outlier removal and gap-filling algorithms}

Figure 12 shows the results of outlier removal and gap-filling algorithms based on the calibrated thresholds. It is observed that most of the conspicuous outliers that are related to meteorological events are well removed. This could also be checked by comparing the scatter plots where most of the outliers that stand out from the majority of the data are removed and the correlation increases after applying the algorithms. However, due to the outliers that remain inside a batch of outliers, it is seen that the SGFA (blue line in Fig. 12) fails to fill short gaps in a few cases. The LGFA (red line in Fig. 12) successfully fills long gaps following the trend of the tide estimation except in the case of May where the gaps appear in front of constant water level data sustained by the malfunctioning of the surge gauge. Since the target data are constant water level data for this case, the results of LGFA show the same results as those of the linear interpolation.

Of course, it is always possible that some outliers remain or gaps are not correctly filled. However, it should be noted that both the outlier removal algorithm and the gap-filling algorithm significantly reduce the chance of discontinuous data with outliers entering the tsunami detection algorithm, which is the main objective of these developments.

\subsection{Performance of tsunami detection algorithm}

In order to investigate the performance of the tsunami detection algorithm, the algorithm should be tested based on an extensive number of tsunamis. However, the 2011 Tōhoku tsunami is the only case that was recorded in the Ulleung-do surge gauge. For stations having insufficient tsunami records, Beltrami and Risio (2011) examined their tsunami detection 

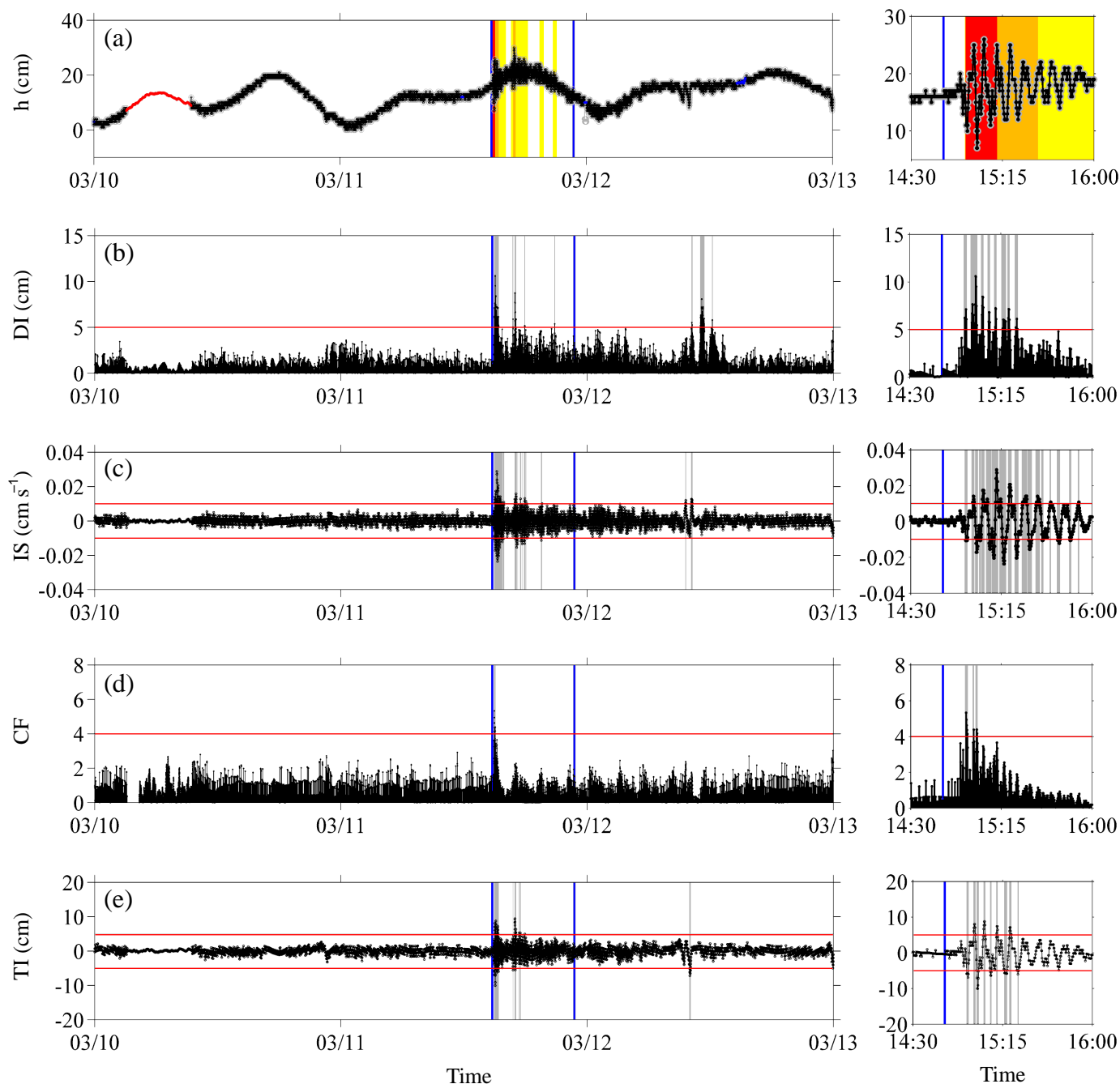

Figure 11. Performance test of TADS for the case of the 2011 Tōhoku tsunami. Blue vertical lines show the event period from 11 March 14:46 LT to 11 March 22:46 LT. For clarity, the records near the tsunami arrival time are zoomed in on the right side. (a) Time series of the Ulleung-do surge gauge after applying the TADS (black line) where outliers are marked by a gray line and gap-filled data are marked by a blue line (SGFA) and red line (LGFA). Vertical lines represent the alarm: warning (red), advisory (orange), and watch (yellow). Four indices of the tsunami detection algorithm are given: (b) DI, (c) IS, (d) CF, and (e) TI. Red horizontal lines represent the thresholds and gray vertical lines mark the time whenever thresholds are triggered.

algorithm with synthetic tsunami signals in which ideal sinusoidal tsunamis were superimposed on ideal wind waves based on JONSWAP (Joint North Sea Wave Project) wave spectra. In addition, Bressan et al. (2013) tested their tsunami detection algorithm with synthetic tsunami signals in which the results of numerical simulations were superimposed on the tide gauge record of possible circumstances (e.g., calm or rough sea). Risio and Beltrami (2014) estimated the performance of the tsunami detection algorithm with historical tsunami signals, in which the record of the DART buoy was superimposed on the wind wave, which in turn was synthesized by means of the random-phase method. Thus, we introduced several synthetic tsunamis to demonstrate the performance of the tsunami detection.
The historical 1983 Akita tsunami $\left(M_{\mathrm{w}}=7.8\right)$ and the 1993 Hokkaido tsunami $\left(M_{\mathrm{W}}=7.7\right)$ were recorded in several tide stations operated by the Korea Hydrographic and Oceanographic Agency (KHOA). Among the records, three records of the tide stations were selected, which are well preserved so that continuous records can be obtained. One is the record of the Ulleung-do tide station in 1983, and others are the records of the Ulleung-do and Pohang tide stations in 1993. Also, even though the amplitude was very small, the 2011 Tōhoku tsunami was recorded in several tide stations. We selected two records of tide stations, Tongyeong and Seongsanpo, which were recorded continuously. The location of tide stations can be found in Fig. 1. 

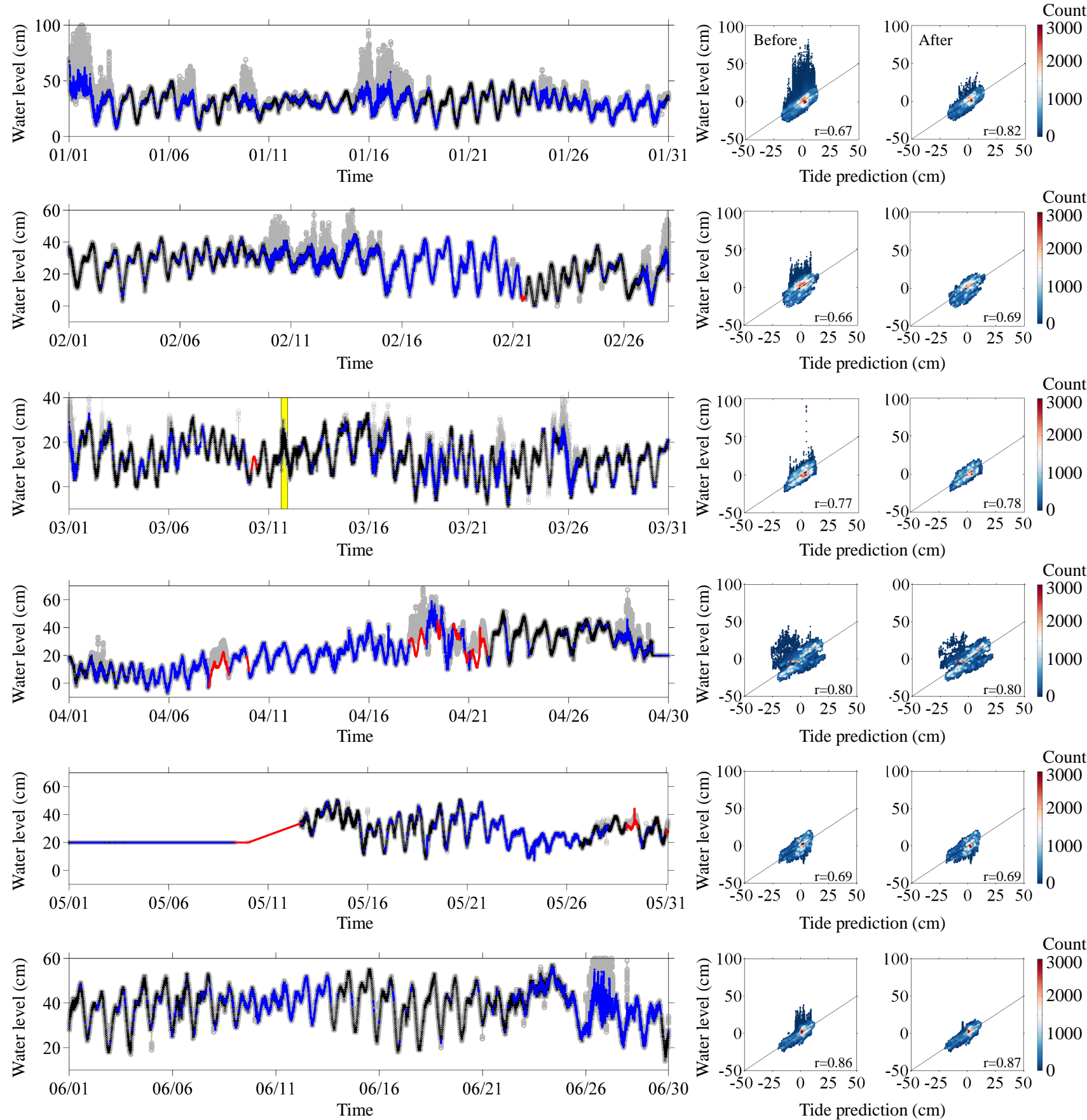

Figure 12.

For the tsunami detection algorithm, one of the important performance indicators is the delay time between the actual arrival time and the time of the first alarm. In order to investigate the delay time, we set the standard arrival time to the arrival time records in the report on tsunami occurrence (KHOA, 2015). However, if the original records are applied to the tsunami detection algorithm directly, it is hard to investigate the delay time correctly because of the false alarm caused by the background records, which are all different depending on the specific local characteristics. Thus, after extracting the tsunami records by detiding the original records, the tsunami records of $24 \mathrm{~h}$ were superimposed on the background records of the Ulleung-do surge gauge. The resulting time series with the alarm level (red, orange, and yellow) are illustrated in Fig. 13. The records of the Ulleung-do tide station show a similar trend with the 2011 Tōhoku tsunami 

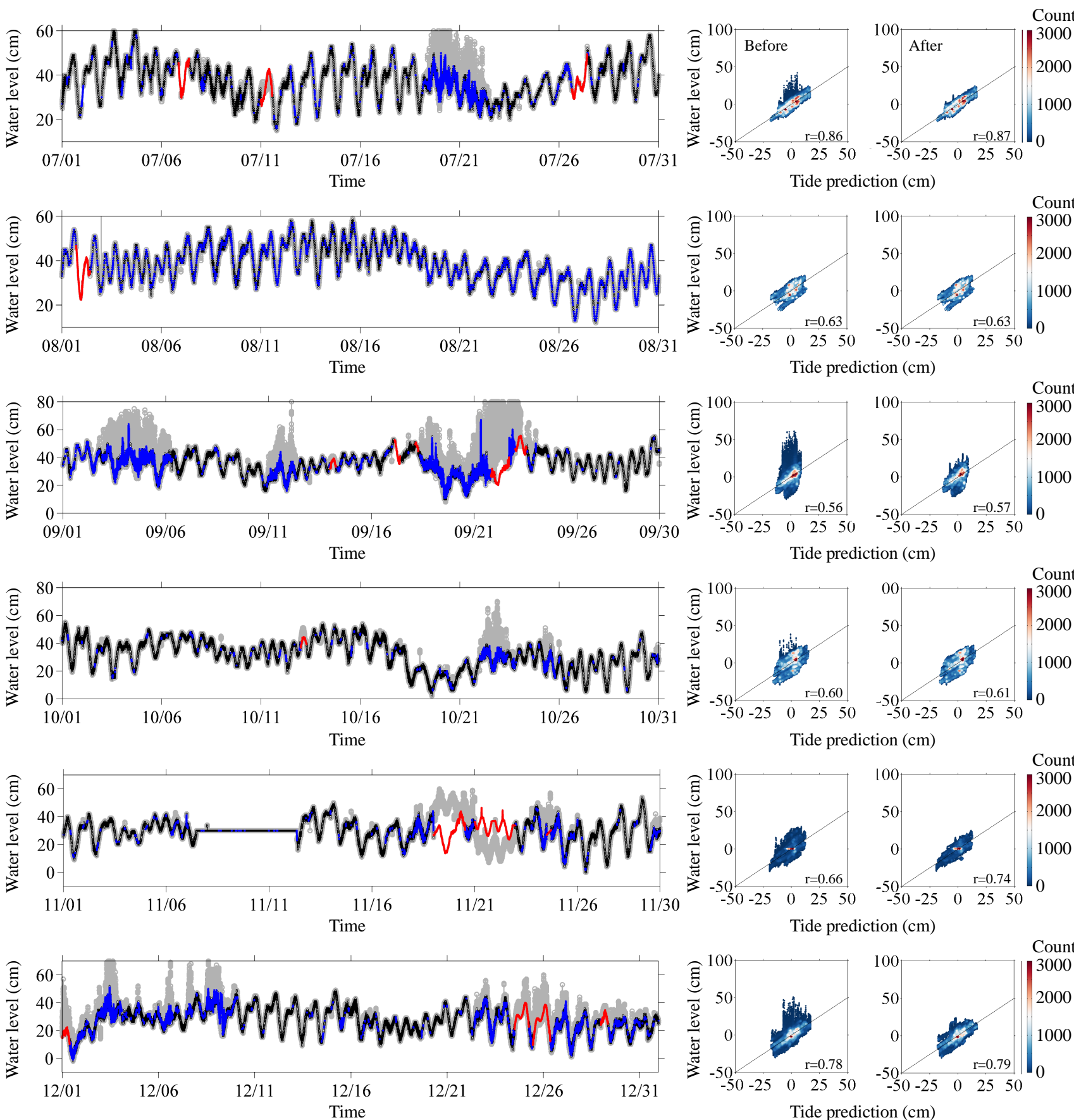

Figure 12. Performance test of the outlier removal and gap-filling algorithms. Left panels: time series of the Ulleung-do surge gauge after applying both outlier removal and gap-filling algorithms (black line). Outliers are marked by a gray line and gap-filled data are marked by a blue line (SGFA) and a red line (LGFA). The yellow box in March indicates the event period. Scatter plots show the comparison between before and after applying both outlier removal and gap-filling algorithms (middle and right). The mean value of each axis in the scatter plot is fixed to zero by subtracting the mean value of each datum from its data. The color point represents the frequency of data plotted inside the circle with a radius of $1 \mathrm{~cm}$. The right corner represents the correlation coefficients. 
(a) 1983 ULD

(b) 1993 ULD

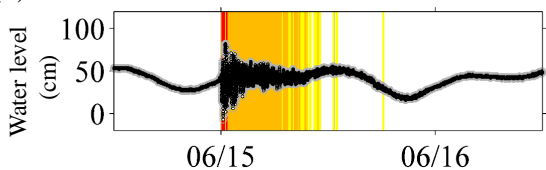

(c) $1993 \mathrm{POH}$

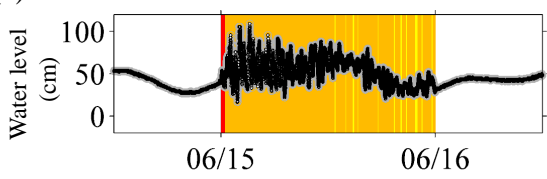

(d) 2011 TOY

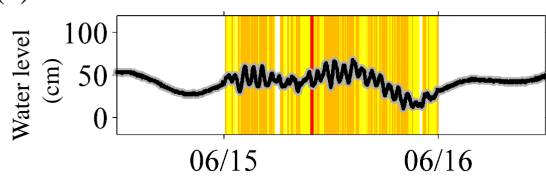

(e) $2011 \mathrm{SSP}$

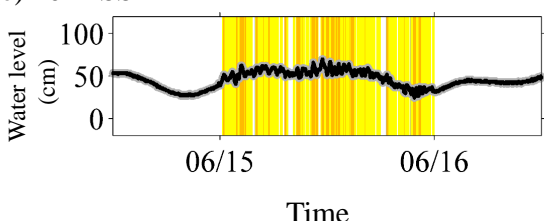

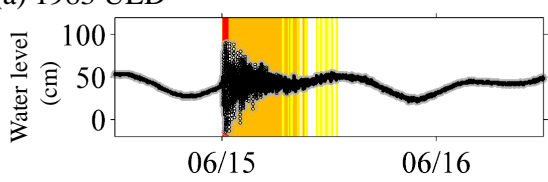
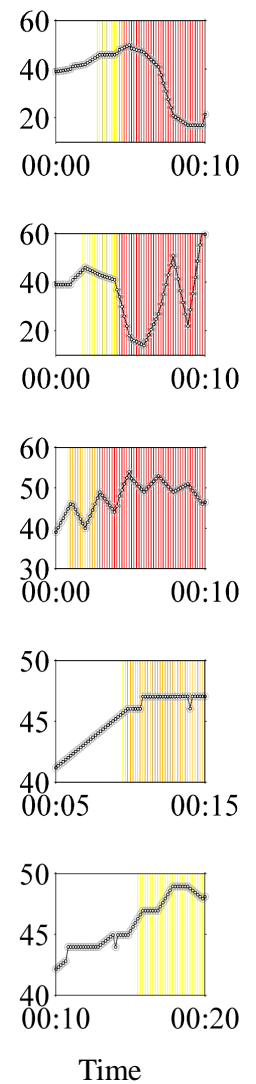

Figure 13. Synthetic tsunami records combining the records of tide stations with the background records of the Ulleung-do surge gauge: (a) 1983 ULD (Ulleung-do), (b) 1993 ULD (Ulleungdo), (c) 1993 POH (Pohang), (d) 2011 TOY (Tongyeong), and (e) $2011 \mathrm{SSP}$ (Seongsanpo). For clarity, the records near the tsunami arrival time are zoomed in on the right side. The arrival time is fixed to 15 June 2011 , and the event period is set to $24 \mathrm{~h}$. Vertical lines represent the alarm: warning (red), advisory (orange), and watch (yellow).

record of the Ulleung-do surge gauge where the amplitude relented after the tsunami arrived (Fig. 13a and b). Conversely, the records of the Pohang, Tongyeong, and Seongsanpo tide stations oscillate consistently (Fig. 13c-e). In general, one could expect that the larger the tsunami amplitude during the same time period, the shorter the delay time is. Indeed, the delay time was shorter than about 5 min for the records of the historical tsunamis (Fig. 13a-c), while the delay time was longer than about $10 \mathrm{~min}$ for the records of the 2011 Tōhoku tsunami (Fig. 13d and e). Because of the small amplitude, the record of the Tongyeong tide station shows the warning alarm (red vertical line) at about $9 \mathrm{~h}$ after the arrival time, and the record of the Seongsanpo tide station shows no warning alarm. However, it should be noted that the tsunami detection algorithm detects a weak tsunami, which is hard to distinguish by visual inspection.

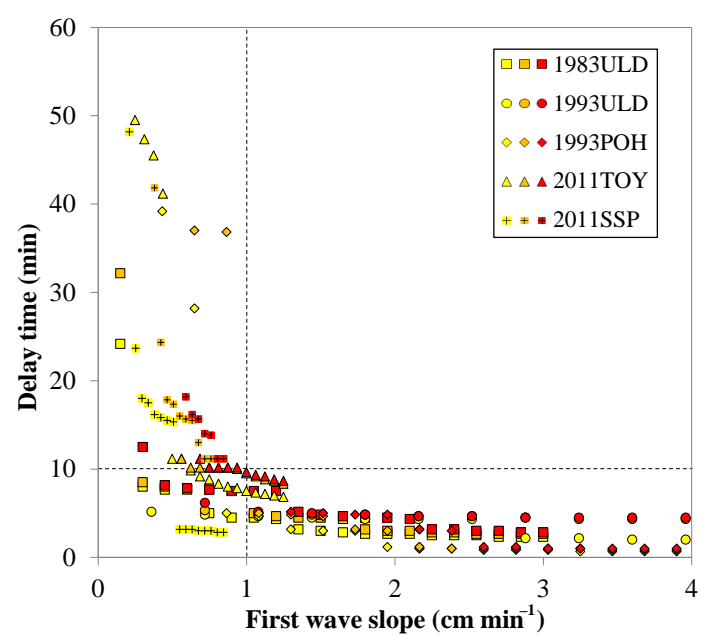

Figure 14. Performance test of the tsunami detection algorithm. The delay times are depicted distinctly depending on the types of synthetic tsunamis: 1983 ULD (rectangle), 1993 ULD (circle), 1993 POH (diamond), 2011 TOY (triangle), and 2011 SSP (cross). The types of alarms are depicted distinctly: warning (red), advisory (orange), and watch (yellow).

For further investigation of the relationship between the first wave slope and the delay time, 100 cases of synthetic tsunami records were built. The detided tsunami records were multiplied by the factor changing from 0.1 to 2.0 with 0.1 intervals, and then the records were superimposed on the background records. Figure 14 shows the delay times of each alarm level (red, orange, and yellow) against the first wave slope of all 100 cases. The first wave slope was defined as the rate of change in the water level between the point of arrival time and the local maximum point that appears after the arrival time with respect to time. As we expected, the distribution shows that the first wave slope and the delay time are in inverse proportion. If the first wave slope is less than about $0.15 \mathrm{~cm} \mathrm{~min}^{-1}$, which is the case of tsunamis that arrive with slowly increasing waves, the tsunami detection algorithm could not issue the warning alarm for any case. However, it should be noted that the tsunami detection algorithm ensures performance when an alarm for the first wave slope larger than $1 \mathrm{~cm} \mathrm{~min}^{-1}$ can be sent within $10 \mathrm{~min}$. In other words, the results show that the tsunami detection algorithm could detect a tsunami whose amplitude is larger than $10 \mathrm{~cm}$ within $10 \mathrm{~min}$.

\section{Conclusion}

In the present study, we proposed a Tsunami Arrival time Detection System (TADS) applicable to discontinuous time series data with outliers. In order to avoid false alarms and time delays, TADS comprises three major algorithms: outlier removal, gap filling, and tsunami detection. The outlier removal algorithm is designed to remove outliers very 
quickly within the time interval of data acquisition. The gapfilling algorithm is designed to fill gaps efficiently by applying different methods depending on the gap size. The tsunami detection algorithm is designed to not only detect weak tsunamis but also to reduce false alarms by combining several algorithms.

TADS recognized the tsunami within a few minutes after its arrival for the 2011 Tōhoku tsunami record from the Ulleung-do surge gauge. Applying TADS to the 1 year dataset and synthetic tsunamis also proved that the overall performance of TADS is effective at detecting a tsunami signal superimposed on both the outliers and gaps. We expect that the efficiency and simplicity of TADS will enable its wide application in tsunami monitoring areas as a support tool that averts calamity by providing a rapid confirmation of tsunami generation.

\section{Data availability}

The Ulleung-do surge gauge data are not available to the public. For scientific collaboration and data usage, interested researchers are asked to contact the authors.

Acknowledgements. This study was supported by the "Research and Development for KMA Weather, Climate and Earth System Services" project of the National Institute of Meteorological Sciences.

Edited by: I. Didenkulova

Reviewed by: J. S. Sepic and one anonymous referee

\section{References}

Beltrami, G. M.: An ANN algorithm for automatic, real-time tsunami detection in deep-sea level measurements, Ocean Eng., 35, 572-587, 2008.

Beltrami, G. M.: Automatic, real-time detection and characterization of tsunamis in deep-sea level measurements, Ocean Eng., 38, 1677-1685, 2011.

Beltrami, G. M. and Risio, M. D.: Algorithms for automatic, realtime tsunami detection in wind-wave measurements Part I: Implementation strategies and basic tests, Coastal Eng., 58, 10621071, 2011.

Bressan, L. and Tinti, S.: Structure and performance of a realtime algorithm to detect tsunami or tsunami-like alert conditions based on sea-level records analysis, Nat. Hazards Earth Syst. Sci., 11, 1499-1521, doi:10.5194/nhess-11-1499-2011, 2011.

Bressan, L. and Tinti, S.: Detecting the 11 March 2011 Tohoku tsunami arrival on sea-level records in the Pacific Ocean: application and performance of the Tsunami Early Detection Algorithm (TEDA), Nat. Hazards Earth Syst. Sci., 12, 1583-1606, doi:10.5194/nhess-12-1583-2012, 2012.

Bressan, L., Zaniboni, F., and Tinti, S.: Calibration of a realtime tsunami detection algorithm for sites with no instrumental tsunami records: application to coastal tide-gauge stations in eastern Sicily, Italy, Nat. Hazards Earth Syst. Sci., 13, 3129 3144, doi:10.5194/nhess-13-3129-2013, 2013.

Cho, Y.-S. and Lee, J.-W.: Hazard Map with Probable Maximum Tsunamis, in: Proceedings of the 23th International Offshore and Polar Engineering Conference, 30 June-5 July 2013, Alaska, USA, 82-85, 2013.

Ehrentreich, F. and Sümmchen, L.: Spike removal and denoising of Raman spectra by wavelet transform methods, Anal. Chem., 73, 4364-4373, 2001.

Elshorbagy, A., Simonovic, S. P., and Panu, U. S.: Estimation of missing streamflow data using principles of chaos theory, J. Hydrol., 255, 123-133, 2002.

Feuerstein, D., Parker, K. H., and Boutelle, M. G.: Practical methods for noise removal: applications to spikes, nonstationary quasi-periodic noise, and baseline drift, Anal. Chem., 81, 49874994, 2009.

Goring, D. G. and Nikora, V. I.: Despiking acoustic Doppler velocimeter data, J. Hydraul. Eng., 128, 117-126, 2002.

Gupta, M., Gao, J., Aggarwal, C., and Han, J.: Outlier detection for temporal data: a survey, IEEE T. Knowledge Data Eng., 26, 2250-2267, 2014.

Hill, D. J. and Minsker, B. S.: Anomaly detection in streaming environmental sensor data: A data-driven modeling approach, Environ. Model. Softw., 25, 1014-1022, 2010.

Hill, D. J., Minsker, B. S., and Amir, E.: Real-time Bayesian anomaly detection in streaming environmental data, Water Resour. Res., 45, 1-16, 2009.

Jesson, M., Sterling, M., and Bridgeman, J.: Despiking velocity time-series - Optimisation through the combination of spike detection and replacement methods, Flow Meas. Instrum., 30, 45$51,2013$.

Jesson, M. A., Bridgeman, J., and Sterling, M.: Novel software developments for the automated post-processing of high volumes of velocity time-series, Adv. Eng. Softw., 89, 36-42, 2015.

Joseph, A.: Tsunamis: Detection, Monitoring, and Early-Warning Technologies, Academic Press, San Diego, USA, 2011.

KHOA - Korea Hydrographic and Oceanographic Agency: The occurrence of tsunamis: analysis of tsunami records, Oceanic Abnormal Phenomena Report, Busan, Korea, 2015.

Lee, J.-W. and Park, S.-C.: Development of a gap-filling algorithm applicable to a tsunami warning system, in: Proceedings of the 25th International Ocean and Polar Engineering Conference, $21-$ 26 June 2015, Hawaii, USA, 860-864, 2015.

Lee, J.-W. and Park, S.-C.: Artificial Neural Network-Based Data Recovery System for the Time Series of Tide Stations, J. Coast. Res., 32, 213-224, 2016.

Lee, J.-W., Park, S.-C., and Park, E. H.: Analysis of arrival time of the 2011 Tohoku, Japan Earthquake and tsunami measured in Korea, in: Proceedings of Earthquake Engineering Society of Korea Fall Conference, 10-12 September 2015, Jeju-do, Korea, 143-144, 2015.

Meinig, C., Stalin, S. E., Nakamura, A. I., and Milburn, H. B.: Realtime deep-ocean tsunami measuring, monitoring, and reporting system: The NOAA DART - description and disclosure, Oceans 2005 MTS/IEEE, Washington, D.C., 2005.

Mofjeld, H. O.: Tsunami detection algorithm, http://www.ndbc. noaa.gov/dart/algorithm.shtml (last access: 29 April 2016), 1997. 
Nitsure, S. P., Londhe, S. N., and Khare, K. C.: Prediction of sea water levels using wind information and soft computing techniques, Appl. Ocean Res., 47, 344-351, 2014.

Pashova, L. and Popova, S.: Daily sea level forecast at tide gauge Burgas, Bulgaria using artificial neural networks, J. Sea Res., 66, 154-161, 2011.

Pawlowicz, R., Beardsley, B., and Lentz, S.: Classical tidal harmonic analysis including error estimates in MATLAB using T_TIDE, Comput. Geosci., 28, 929-937, 2002.

Pérez, B., Álvarez Fanjul, E., Pérez, S., de Alfonso, M., and Vela, J.: Use of tide gauge data in operational oceanography and sea level hazard warning systems, J. Oper. Oceanogr., 6, 1-18, 2013.

Pugh, D. and Woodworth, P.: Sea-Level Science: Understanding Tides, Surges, Tsunamis and Mean Sea-Level Changes, Cambridge University Press, Cambridge, UK, 2014.

Risio, M. D. and Beltrami, G. M.: Algorithms for automatic, real-time tsunami detection in wind-wave measurements: using strategies and practical aspects, Procedia Eng., 70, 545-554, 2014.
Tolkova, E.: Principal component analysis of tsunami buoy record: Tide prediction and removal, Dyn. Atmos. Oceans, 46, 62-82, 2009.

Ustoorikar, K. and Deo, M. C.: Filling up gaps in wave data with genetic programming, Mar. Struct., 21, 177-195, 2008.

Yamanishi, K. and Takeuchi, J. I.: A unifying framework for detecting outliers and change points from non-stationary time series data, in: Proceedings of the 8th ACM SIGKDD international conference on Knowledge discovery and data mining, 2326 July 2002, Alberta, Canada, 676-681, 2002.

Yoon, S. B., Baek, U., Park, W. K., and Bae, J. S.: Practical forecastwarning system for distant tsunamis, J. Korea Water Resour. Assoc., 45, 997-1008, 2012.

Yoon, S. B., Shin, C. H., and Bae, J. S.: Analysis of Generation and Amplification Mechanism of Abnormal Waves Occurred along the West Coast of Korea, J. Korean Soc. Coast. Ocean Eng., 26, 314-326, 2014. 